\title{
DSCAM Promotes Refinement in the Mouse Retina through Cell Death and Restriction of Exploring Dendrites
}

\author{
[DShuai Li, ${ }^{1 \star}$ Joshua M. Sukeena, ${ }^{1 \star}$ Aaron B. Simmons, ${ }^{1}$ Ethan J. Hansen, ${ }^{1}$ Renee E. Nuhn, ${ }^{1,4}$ Ivy S. Samuels, ${ }^{2,3}$ \\ and DPeter G. Fuerst ${ }^{1,4}$ \\ ${ }^{1}$ University of Idaho, Department of Biological Sciences, Moscow, Idaho 83844, ${ }^{2}$ Cole Eye Institute, Cleveland Clinic, Cleveland, Ohio 44106, ${ }^{3}$ Louis Stokes \\ Cleveland VA Medical Center, Cleveland, Ohio 44195, and ${ }^{4}$ WWAMI Medical Education Program, Moscow, Idaho 83844
}

In this study we develop and use a gain-of-function mouse allele of the Down syndrome cell adhesion molecule (Dscam) to complement loss-of-function models. We assay the role of Dscam in promoting cell death, spacing, and laminar targeting of neurons in the developing mouse retina. We find that ectopic or overexpression of Dscam is sufficient to drive cell death. Gain-of-function studies indicate that Dscam is not sufficient to increase spatial organization, prevent cell-to-cell pairing, or promote active avoidance in the mouse retina, despite the similarity of the Dscam loss-of-function phenotype in the mouse retina to phenotypes observed in Drosophila Dscam1 mutants. Both gain- and loss-of-function studies support a role for Dscam in targeting neurites; DSCAM is necessary for precise dendrite lamination, and is sufficient to retarget neurites of outer retinal cells after ectopic expression. We further demonstrate that DSCAM guides dendrite targeting in type 2 dopaminergic amacrine cells, by restricting the stratum in which exploring retinal dendrites stabilize, in a Dscam dosage-dependent manner. Based on these results we propose a single model to account for the numerous Dscam gain- and loss-of-function phenotypes reported in the mouse retina whereby DSCAM eliminates inappropriately placed cells and connections.

Key words: apoptosis; bax; dendrite; ERG; mosaic; physiology

\section{Introduction}

Proper retinal neuron circuitry is achieved by an elegant orchestration of signaling mediated by transmembrane molecules and synaptic activity (Masland, 2012; Randlett et al., 2013; Okawa et al., 2014). Organization of retinal neurites into the inner and outer plexiform layers (IPL and OPL) is accomplished in part by transmembrane semaphorins and their cognate plexin receptors (Matsuoka et al., 2011a,b; Sun et al., 2013). Homophilic cell adhesion molecules, including cadherins (Duan et al., 2014), contactins (Yamagata and Sanes, 2012), Down syndrome cell adhesion molecules (Dscams), and sidekicks (Yamagata and Sanes, 2008), regulate neurite targeting through adhesion. Avoidance is also essential for development of the retina, with multiple EGF-like domains proteins (Kay et al., 2012), DSCAMs (Fuerst et al., 2009), and the $\gamma$-protocadherin proteins (Lefebvre et al., 2012) required to prevent interactions.

\footnotetext{
Received May 30, 2014; revised Feb. 18, 2015; accepted Feb. 21, 2015

Author contributions: P.G.F. designed research; S.L., J.M.S., A.B.S., E.J.H., I.S.S., and P.G.F. performed research; S.L., J.M.S., R.E.N., I.S.S., and P.G.F. analyzed data; I.S.S. and P.G.F. wrote the paper.

This research was supported by the National Eye Institute Grant EY020857 and a Department of Veteran Affairs Career Development Award (I.S.S.). Imaging support was provided by National Institutes of Health grants P20 RR016454, P30 GM103324-01, and P20 GM103408. We appreciate suggestions from Benjamin Reese, Deborah Stenkamp, and Neal Peachey. We appreciate Brenda Hanley's help with developing software used to demarcate the IPL.

*S.L. and J.M.S. contributed equally to this work.

The authors declare no competing financial interests.

Correspondence should be addressed to Peter G. Fuerst, Department of Biological Sciences, WWAMI Medical Education Program, University of Idaho, Moscow, Idaho 83844. E-mail: fuerst@uidaho.edu.

DOI:10.1523/JNEUROSCI.2202-14.2015

Copyright $\odot 2015$ the authors $\quad 0270-6474 / 15 / 355640-15 \$ 15.00 / 0$
}

As noted, DSCAM proteins provide both adhesive and repulsive developmental cues. DSCAM proteins have been most thoroughly studied in Drosophila, where the splice diversity of Dscam1 (Schmucker et al., 2000; Neves et al., 2004) facilitates neuron-specific avoidance (Chen et al., 2006), synaptic pairing (Zhu et al., 2006), neurite outgrowth (Hutchinson et al., 2014), and projection of axon collaterals (He et al., 2014). Extensive Dscam alternative splicing is not observed in non-insect model organisms (Schmucker and Chen, 2009), and yet many of the functions Dscam 1 mediates in Drosophila are conserved in other systems. Dscam plays a role in synaptic pairing in Aplysia (Li et al., 2009), and mediates axon guidance in zebrafish (Yimlamai et al., 2005), chick (Ly et al., 2008), mouse (Liu et al., 2009), and Xenopus (Morales Diaz, 2014). Importantly, requirements for Dscam in avoidance in mouse (Fuerst et al., 2008, 2009) and targeting in chick (Yamagata and Sanes, 2008, 2010) have been identified in development of the retina.

These roles are consistent with findings that implicate Dscam in contributing to human neurological disorders. Changes to the branching and spine density of cortical neurons observed in Dscam mutant mice mirror changes observed in humans with Down syndrome (DS) (Maynard and Stein, 2012). This is further supported by overexpression studies in hippocampal neuron cultures, in which DSCAM inhibits branching (Alves-Sampaio et al., 2010). Misregulation of Dscam levels in fragile X syndrome has also been linked to synaptic defects and mistargeting (Cvetkovska et al., 2013; Kim et al., 2013). Dscam dose-dependent phenotypes have been identified in the visual system (Blank et al., 2011) and people with DS have a high incidence of visual deficiency (Creavin and Brown, 2009). Given the large number of disorders 
associated with Dscam, it is essential to determine the precise nature of the gene's function in model organisms.

Here we report that Dscam is sufficient to drive cell death but not avoidance in the mouse retina. Gain- and loss-of-function analysis is then combined to assay Dscam function in neurite targeting and refinement. We find that mouse Dscam is both necessary and sufficient to target retinal neurites. We further demonstrate mechanisms by which DSCAM promotes refinement of dendrites.

\section{Materials and Methods}

Dscam ${ }^{\text {floxGOF }}$ mice. A conditional expression construct with a dual fluorescent reporter under control of the CAG promoter was generated. The backbone of this construct is the pCAG-IG (Internal Ribosome Entry Sequence GFP) plasmid (obtained from Addgene; courtesy of Dr. Connie Cepko; Matsuda and Cepko, 2004). A floxed tandem dimer RFP was PCR amplified from the brainbow 2.1 plasmid, including the poly-A sites from the pcDNA series vectors (obtained from Addgene; courtesy of Dr. Joshua Sanes; Livet et al., 2007). This sequence was inserted into the EcoRI/NotI sites of the pCAG-IG plasmid (NCBI Bankit ID: 1714400). Full-length mouse Dscam was amplified from mouse brain cDNA in four individual segments and inserted into the vector pSL1180 (courtesy of Drs. Daniel Voytas and Robert Burgess; NCBI Bankit ID: 1714413). DNA was linearized to remove the viral replication sequences incorporated into the CAG series of plasmid and then microinjected into one-cell mouse embryos by the University of Washington transgenic facility. Five founders were generated from 150 injections. All experiments in this manuscript were performed with mice resulting from a single founder to ensure consistency of expression. This strain is available through The Jackson Laboratory (stock number: 025543).

Mouse strains and handling. Pax $6 \alpha$-Cre mice effectively targeted the Dscam ${ }^{\text {floxGOF }}$ transgene in retinal neurons and Müller glia in the lateral retina, while inactivation of RFP and expression of Dscam and GFP was limited to a subset of amacrine cells in a dorsoventral wedge of the retina, as previously reported by others (Stacy et al., 2005; Lefebvre et al., 2008). At the margins of these two domains mixed columns in which only amacrine cells were targeted or in which all neurons and Müller glia were targeted were often observed intermixed. Dscam ${ }^{2 J}$ mice, which do not make a DSCAM protein that is detectable by either Western blot analysis or immunohistochemistry, were used in physiology experiments (Schramm et al., 2012; de Andrade et al., 2014). Dscam ${ }^{F D}$ mice are derived from germline targeting of a previously reported conditional allele of Dscam and were used in all experiments except for physiology recordings (Fuerst et al., 2012). The exon encoding the Dscam transmembrane domain was flanked by loxP sites, and was deleted in this allele, and as a result the protein fails to target to the plasma membrane. Both Dscam ${ }^{F D}$ and $D$ scam ${ }^{2 J}$ alleles are referred to as Dscam loss-of-function $\left(D s c a m^{L O F}\right)$ to contrast them with the gain-of-function allele $\left(D_{s c a m}{ }^{G O F}\right)$. Dscam ${ }^{L O F}$ refers to homozygous mutants, while heterozygotes are referred to as $\mathrm{Dscam}^{\mathrm{LOF} /+}$. Bax-null mice were acquired from The Jackson Laboratory (Knudson et al., 1995). TH-GFP mice express GFP brightly in type 2 dopaminergic amacrine cells (DACs) and more dimly in type 1 DACs (Knop et al., 2011). TH-GFP mice were a kind gift from Dr. Suzy Appleyard, Washington State University. All mice were housed on a $12 \mathrm{~h}$ light/ dark cycle and fed ad libitum. Mice used in this study were maintained on a mixed C57 BL/6J, C3H/HeJ, and 129/P background except for mice carrying the $D$ scam ${ }^{2 J}$ allele, which are carried on an inbred C3H/HeJ background. The defective allele of $P d e 6 b$ was crossed out of the $\mathrm{C} 3 \mathrm{H} /$ HeJ mice. Mice of either sex were used for analysis in all experiments. All procedures performed on mice used in this study were approved by the University of Idaho Animal Care and Use Committee or by the Cleveland Clinic Institutional Animal Care and Use Committee and were in accordance with the Institute for Laboratory Animal Research Guide for Care and Use of Laboratory Animals.

Genotyping. Tissue biopsies were boiled in sodium hydroxide and neutralized in Tris $\mathrm{Cl}, \mathrm{pH}$ 5.0. PCR was performed using one-shot master mix supplemented with primers. Genotyping has previously been described for all strains (Fuerst et al., 2010, 2012). Dscam ${ }^{G O F}$ mice were genotyped by the presence of RFP (carries transgene), GFP (carries recombined transgene), or no fluorescent protein (does not carry the transgene).

Immunocytochemistry and immunohistochemistry. Mice were perfused with PBS. Retinas were hemisected and fixed in 4\% PFA for either $30 \mathrm{~min}$ at room temperature (worked for all staining except for DSCAM) or for $50 \mathrm{~min}$ on ice (worked for all staining but is suboptimal for staining of some cytoplasmic proteins). Tissues to be embedded in wax were fixed in 1:3 acetic acid:methanol for $2-12 \mathrm{~h}$ (paraffin sections gave equivalent antibody staining except for DSCAM, melanopsin, and vglut3 staining). Tissue was stained as previously described (de Andrade et al., 2014).

Antibodies and stains. Mouse anti-DSCAM (R\&D Technologies; MAB36661; 1:25), rabbit anti-cone arrestin (cones; Millipore; AB15282; 1:5000), rabbit anti-recoverin (rods; Millipore; AB5585; 1:2000), rabbit anti-Ibal (microglia; Wako; 1:500), rabbit anti-Dab1 (AII-amacrine cells; generous gift from Brian Howell; 1:500), goat anti-ChAT (starburst amacrine cells; Millipore; AB144P; 1:400), rabbit anti-calbindin (horizontal cells; Swant; CB38a; 1:1000), rabbit anti-bNOS (bNOS-amacrine cells; Sigma-Aldrich; NZ280; 1:15,000), mouse anti-PKC $\alpha$ (rod bipolar cells; Santa Cruz Biotechnology; sc8393; 1:500), mouse anti-HCN4 (type 3A cone bipolar cells; Alomone Labs; 1:500), mouse anti-PKARII $\beta$ (type 3B cone bipolar cells; BD Biosciences; P54720; 1:500), mouse antidystroglycan (OPL synapses; Developmental Studies Hybridoma Bank; 1:500), rabbit anti-TH (type 1 DACs; Millipore Bioscience Research Reagents; 1:500), mouse anti-GS (Müller glia; BD Transduction Laboratories; 610517; 1:2000), mouse anti-PSD-95 (OPL synapses; NeuroMab; 75-028; 1:200), rabbit anti-melanopsin (melanopsin-positive retinal ganglion cells; generous gift from Ignacio Provencio; 1:5000), mouse anti-TH (type 1 DACs; Novacastra; 1:50), guinea pig anti-vglut3 (vglut3amacrine cells; Millipore; 1:5000), and rabbit anti-phosphohistone $\mathrm{H} 3$ (Cell Signaling Technology; 1:500). DAPI reagent was mixed into the second wash after incubation with secondary antibodies at a dilution of 1:50,000 of a $1 \mathrm{mg} / \mathrm{ml}$ stock. DRAQ5 (Cell Signaling Technology) was used at a 1:1000 dilution incorporated with secondary antibodies. For TUNEL staining sections were stained with an in situ cell death kit (Roche). Secondary antibodies were acquired from Jackson ImmunoResearch and used at a concentration of 1:1000.

Cell counts. Tissue was coded before analysis and counts were performed in a blinded fashion. TUNEL or phosphohistone $\mathrm{H} 3(\mathrm{pH} 3)-$ positive cells were counted in images of retina sections. The position of TUNEL-positive cells was recorded based on which of the three retinal layers they were localized within. Cell type counts: Müller glia, type 1 and 2 DACs, AII amacrine cells, horizontal cells, and starburst amacrine cells were counted in at least four whole retinas. Other cell types were counted in at least four sections from at least three retinas and normalized per length of retina. Nuclei counts: retinal sections were stained with DRAQ5 and imaged intermediate between the optic nerve and periphery. Columns of cells in the outer nuclear layer, inner nuclear layer, and retinal ganglion cell layer were counted in four areas for each of nine images collected from three different retinas. The number of cells in the IPL was counted for each image in a given area. For type 2 DAC lamination analysis the number of type 2 DAC cells that have dendrites running through S1, both those that terminate in S1 and those that later ascend to S3, were counted in at least six sections from at least three retinas for each age and genotype and reported as the percentage of cells that extend dendrites into S1. Each cell was given a binary value depending on whether it projected dendrites into S1. These numbers were used to test the significance using a Student's $t$ test.

Microscopy. An Olympus DSU spinning disk confocal microscope and Olympus FluoView confocal microscope were used to capture all fluorescent images. A Nikon epifluorescent microscope was used to capture images of H\&E sections. Any modification to images, for example, to brightness, was performed across the entire image in accordance with the journal's standards.

Density recovery profile, nearest neighbor analysis, and Voronoi analysis. Spacing analysis was conducted as previously described (Rodieck, 1991; Khiripet et al., 2012). Density recovery profile (DRP) analysis is a measure of the tendency of cells of the same subtype to occupy space located in close proximity to other cells of the same subtype. Cells that avoid cells 
of the same subtype result in a DRP that includes an exclusion zone, which is evidenced by annuli cell densities that fall below the average cell density. To control for cell density, the packing index was used in statistical tests. The packing index is a measure of organization compared with the most highly spaced possible organization of a given number of cells, that is, if cells were arranged in a hexagonal pattern. Nearest neighbor analysis (NNA) measures the distance from one cell to the nearest cell of the same subtype, which is increased compared with random simulations if cells space themselves to avoid cells of the same subtype. To control for cell density the nearest neighbor regularity index (NNRI) was used in statistical tests. Spacing of cells using Voronoi analysis measures the regularity of spacing with respect to cells of the same subtype. The Voronoi domains (VDs) of different populations can be compared using the coefficient of variance $(\mathrm{CoV})$, the ratio of the $\mathrm{SD}$ to the mean.

The programs winDRP or Ka-me (Khiripet et al., 2012) were used to assay the spacing of type 1 and 2 DACs, AII amacrine cells, horizontal cells, and starburst amacrine cells. Whole retinas were imaged in analysis of type 1 and 2 DACs. The $-640^{2} \mu \mathrm{m}$ fields of OFF starburst amacrine cells, AII amacrine cells, and horizontal cells were sampled from dorsal, ventral, and lateral planes midway between the optic disk and periphery of the retina. A minimum of six fields sampled from at least three mice was used for each analysis.

Electron microscopy. Retinas were fixed in cacodylate/glutaraldehyde buffer. Serial electron micrographs were taken at $7 \mathrm{~nm}$ resolution every $40-60 \mathrm{~nm}$ by Renovo Imaging. Representative synapses were identified by analyzing serial images of rod and cone photoreceptors.

$E R G$. After overnight dark adaptation, mice were anesthetized with ketamine $(80 \mathrm{mg} / \mathrm{kg})$ and xylazine $(16 \mathrm{mg} / \mathrm{kg})$. Eye drops were used to anesthetize the cornea ( $1 \%$ proparacaine $\mathrm{HCl}$ ) and to dilate the pupil (2.5\% phenylephrine $\mathrm{HCl}, 1 \%$ tropicamide, and $1 \%$ cyclopentolate $\mathrm{HCl})$. Mice were placed on a temperature-regulated heating pad throughout the recording session.

Strobe flash ERGs were recorded using a stainless steel electrode in contact with the corneal surface. Needle electrodes were placed in the cheek and the tail for reference and ground leads, respectively. Darkadapted responses were presented within an LKC Ganzfeld and recorded using flash intensities that ranged from -3.6 to $2.1 \log \mathrm{cd} \mathrm{s} / \mathrm{m}^{2}$. Stimuli were presented in order of increasing intensity, and the number of successive responses averaged together decreased from 20 for low-intensity flashes to 2 for the highest intensity stimuli. Conversely, the duration of the interstimulus interval increased from $4 \mathrm{~s}$ for low-intensity flashes to $90 \mathrm{~s}$ for the highest intensity stimuli. Following completion of the darkadapted responses, a steady rod-desensitizing adapting field ( $1.5 \log \mathrm{cd} /$ $\mathrm{m}^{2}$ ) was presented within the Ganzfeld bowl. After allowing a $7 \mathrm{~min}$ period of light adaptation, cone ERGs were recorded to flashes superimposed on an adapting field. Flash intensity ranged from -0.8 to $1.9 \log \mathrm{cd}$ $\mathrm{s} / \mathrm{m}^{2}$, and responses to 25 flashes were presented at $2.1 \mathrm{~Hz}$ and averaged at each intensity level. Responses were differentially amplified (0.3-1500 $\mathrm{Hz}$ ), averaged, and stored using a UTAS E-3000 signal averaging system (LKC Technologies).

ERG analysis. The amplitude of the a-wave was measured at $8 \mathrm{~ms}$ after flash presentation from the prestimulus baseline. The amplitude of the $\mathrm{b}$-wave was measured to the b-wave peak from the a-wave trough.

Western blot analysis. Western blot analysis was performed as previously described with the following modifications (Schramm et al., 2012): $30 \mu \mathrm{g}$ of total protein, including both the cytosolic and membrane fractions, was loaded into each well, and protein was transferred to a nitrocellulose membrane.

IPL lamination analysis. The locations of the inner nuclear layer, retinal ganglion cell layer, and peak intensities of the cholinergic amacrine cell dendrites in S2 and S4 were used to demarcate the IPL into strata for analysis. Peak intensity and band percentages were automatically segmented using custom software run in $\mathrm{R}$ based on the location of cholinergic amacrine cell dendrites, the retinal ganglion cell layer, and the inner nuclear layer. Nine images from each genotype were analyzed. MannWhitney $U$ test $p$ value thresholds for significance $(0.01)$ were determined by comparing groups of wild-type retina sections to each other and setting the threshold below values observed in these tests. Tissue was coded before analysis and lamination analysis was performed in a blinded fashion.

Cell culture. Amacrine cells were grown in culture as previously described (Kunzevitzky et al., 2013). Cells were collected at P2 and incubated $2 \mathrm{~d}$ before being fixed and stained for DSCAM.

\section{Results}

\section{Generation of a conditional Dscam gain-of-function mouse model}

We generated a gain-of-function mouse model of Dscam to extend analysis of phenotypes identified in studies using loss-offunction models (Fuerst et al., 2008; Maynard and Stein, 2012). We generated a transgenic mouse model that conditionally expresses Dscam under control of the constitutive CAG promotor (Miyazaki et al., 1989). This allele, denoted as Dscam ${ }^{\text {floxGOF }}$ before Cre-mediated recombination, expresses either RFP, or Dscam and GFP, after Cre-mediated recombination removes the RFP sequence (Fig. 1A). Mice produced by germline activation of Dscam expression $\left(D_{s c a m}{ }^{G O F}\right)$ are viable and fertile, though smaller than littermate controls (Fig. $1 B$; quantified at P11: WT $9.09 \pm 1.8 \mathrm{~g}$ SD vs $4.25 \pm 1.08 \mathrm{~g} \mathrm{SD} ; t$ test $<0.0001 ; n=28)$, and exhibit circling behavior. The transgene is expressed throughout the retina, the focus of this study (Fig. 1C). Increased DSCAM protein was detected in tissue lysates and sections collected from $D s c a m^{G O F}$ mice, including tissues in which the protein is absent or present in low concentrations such as heart (Grossman et al., 2011), and neural tissues (Fig. 1D; data not shown). Tissuespecific conditional activation of recombination was achieved, and resulted in elimination of RFP and production of DSCAM in areas in which Cre recombinase was expressed (Fig. 1E). Localization of DSCAM protein in the $\mathrm{Dscam}^{G O F}$ retina is very similar to the DSCAM localization pattern observed in the wild-type retina (de Andrade et al., 2014; Fig. 1F), except for the presence of DSCAM protein in the outer limiting membrane of the Dscam $^{\text {GOF }}$ allele (Fig. 1E, arrows).

To confirm that the Dscam ${ }^{G O F}$ allele makes functional protein we complemented the dendrite and soma clumping phenotype associated with the Dscam ${ }^{L O F}$ allele. The cell bodies and dendrites of melanopsin-positive retinal ganglion cells (mRGCs) and type 1 DACs are spaced and arborized, respectively, in the wild-type retina (Fig. 1G,H). Clumping phenotypes observed in the $D$ scam $^{L O F}$ retina (Fig. $1 I, J$ ) were rescued by the $D$ scam ${ }^{G O F}$ transgene, demonstrated for both cell types (Fig. $1 K, L$ ).

Using the gain-of-function allele alongside previously developed loss-of-function alleles, we set out to assay $D_{\text {scam }}{ }^{\text {LOF }}$ phenotypes by testing the protein's role in (1) developmental cell death, (2) avoidance and cell spacing, and (3) dendrite lamination and refinement.

\section{Gain-of-function analysis confirms Dscam expression is sufficient to drive cell death}

In the first part of this study we examined the role of Dscam in developmental cell death using $\operatorname{Dscam}^{L O F}$ and Bax-null alleles in conjunction with the Dscam ${ }^{G O F}$ model.

A decrease in cell death was previously reported in the Dscam ${ }^{L O F}$ retina (Fuerst et al., 2008). Compared with the wild-type, the Dscam $^{G O F}$ retina displayed a decrease in cell number at postnatal stages, in addition to aberrant pockets of rods and microglia mixed in with the photoreceptor inner and outer segments (observed in every retina section; Fig. $2 A, B$, arrowheads). Cells were identified based on immunoreactivity with recoverin but not cone arrestin, which accounted for most cells, or with Ibal (data not shown). To test if increased Dscam expression levels promote 

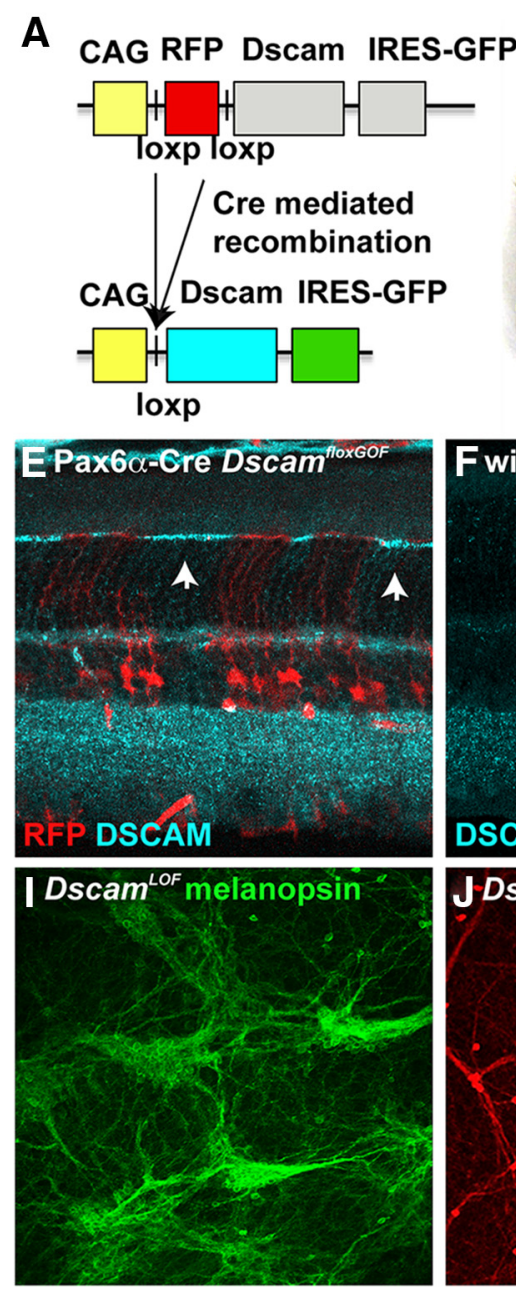
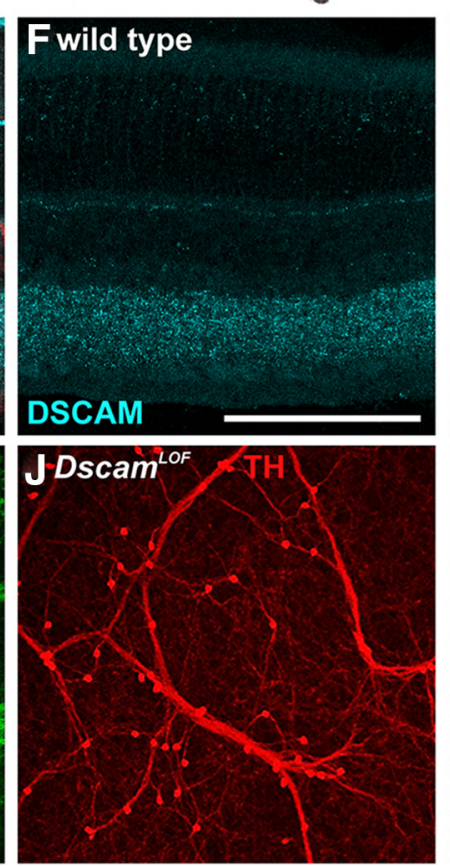
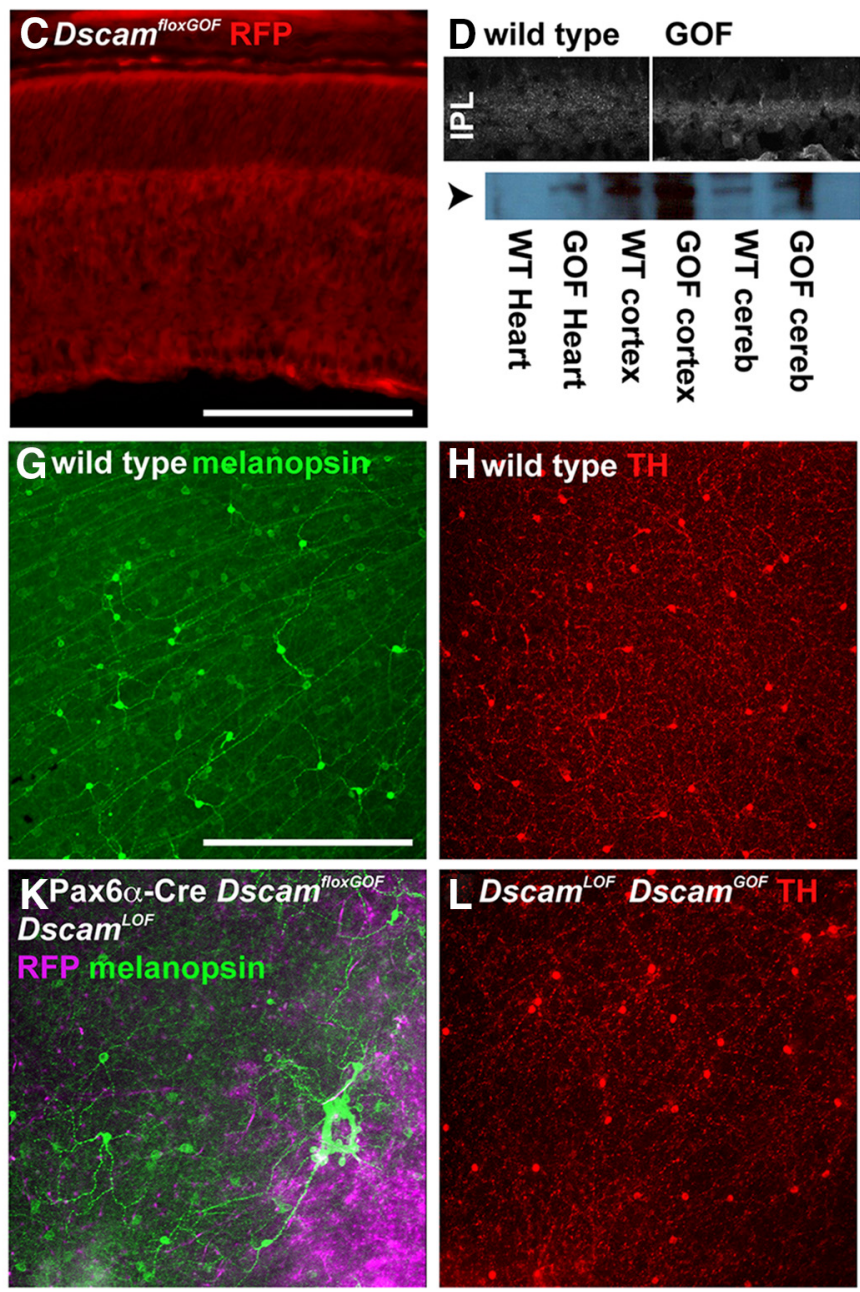

Figure 1. Dscam gain-of-function allele. $\boldsymbol{A}$, A conditional gain-of-function allele of mouse Dscam was generated. $\boldsymbol{B}$, Germline activation of recombination resulted in viable mice that were smaller than littermate controls. C, The transgene was expressed throughout the retina during development. $\boldsymbol{D}$, Immunofluorescence of the retinal IPL and Western blot analysis of DSCAM protein in tissue and tissue lysates from wild-type and Dscam ${ }^{G O F}$ mice. $\boldsymbol{E}$, Mosaic Cre-mediated recombination of the Dscam ${ }^{G O F}$ transgene. $\boldsymbol{F}$, Distribution of DSCAM in the wild-type retina. $\boldsymbol{G}, \boldsymbol{H}$, Spacing and arborization of wild-type mRGCs and DACs. $I, J$, Clustering of Dscam ${ }^{L O F} \mathrm{mRGC}$ and DAC cell bodies and dendrites. $\boldsymbol{K}, \boldsymbol{L}$, Expression of the Dscam ${ }^{G O F}$ transgene is sufficient to rescue loss-of-function clumping phenotypes. P15: B, E, F; P10: C; P7: D; P28-P42: G-L. N>3 for all genotypes. Scale bars: (in C) C, E, $100 \mu \mathrm{m} ; \boldsymbol{F}, 100 \mu \mathrm{m}$; (in $\mathbf{G}) \mathbf{G}-\boldsymbol{L} 400 \mu \mathrm{m}$.

cell death we investigated whether the reduction in cell number in the $D s c a m^{G O F}$ retina was due to changes in cell birth, cell death, or both, by counting the number of dividing and apoptotic cells during development (Fig. 2C,D). A significant increase in cell death, but not cell birth, was observed at time points aligned with the points at which normal developmental cell death occurs in the mouse retina (Fig. 2E). Apoptosis of misplaced rods (Fig. 2B, arrowheads) at P15 (Fig. 2E, ONL P15) and beyond resulted in the elimination of the cell clusters by 8 months of age (Fig. $2 F$ ). Individual cell populations were counted to determine whether Dscam expression level selectively increased cell death in different cell populations. A significant decrease in most cell types of the inner retina was observed compared with wild-type (Fig. 2G). Of note, the one neuron type that was not reduced in number in the inner retina, the type $1 \mathrm{DAC}$, is also unchanged in total number in the $D_{s c a m}{ }^{L O F}$ retina (Keeley et al., 2012). These results indicate that Dscam expression is sufficient to drive developmental cell death.

We next sought to test if BAX, a terminal activator of cell death that accounts for most cell death in the inner, but not outer, retina (Péquignot et al., 2003), was responsible for the increased apoptosis in the Dscam ${ }^{G O F}$ mouse. Cell number was quantified in wild-type,
Dscam ${ }^{\mathrm{LOF} /+}, \mathrm{Dscam}^{\mathrm{LOF}}$, Bax-null $\left(\mathrm{Bax}^{-/-}\right), \mathrm{Dscam}^{\mathrm{LOF}} / \mathrm{Bax}^{-/-}$, $D$ scam ${ }^{G O F}$, and $D s c a m^{G O F} / B^{-1-}$ retinas (Fig. $3 A-G$ ). We first quantified the presence of misplaced neurons in the IPL. Loss of Dscam or Bax resulted in a significant increase in the number of neurons located in the IPL (Fig. $3 H$ ). Elimination of both genes resulted in a significant additive increase in the number of neurons in the IPL, while a significant reduction in IPL cell number was detected in the $D$ scam ${ }^{G O F} / \mathrm{Bax}^{-/-}$retina compared with the $B a x^{-/-}$retina. This revealed that DSCAM and BAX can independently function to eliminate misplaced cells.

Next we assayed cell number in the three nuclear layers of the retina. No significant difference in the number of cells in the outer nuclear layer (ONL) was detected when comparing any of these genotypes (Fig. 3I, ONL; wild-type cell number values are provided in the figure legend; misplaced cells in the Dscam $^{G O F}$ subretinal space were not included in counts). Notable significant differences were detected within the inner retina. We found a significant increase in cell number in the $D s c a m^{L O F} / \mathrm{Bax}^{-1-}$ retina compared with the $D s c a m^{L O F}$ or $\mathrm{Bax}^{-/-}$retina (INL), and decreases in cell number when comparing the $\mathrm{Dscam}^{\mathrm{GOF}} / \mathrm{Bax}^{-/-}$ retina to the $\mathrm{Bax}^{-/-}$retina [INL and retinal ganglion layer (RGL); Fig. 3I]. This revealed that DSCAM and BAX can independently 

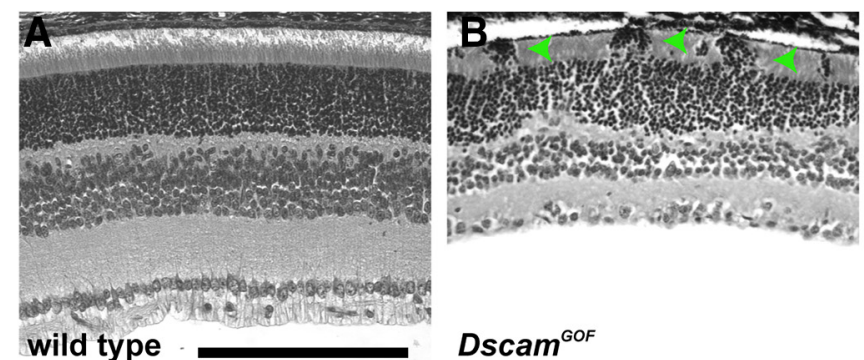

wild type

Dscam $^{\text {GOF }}$

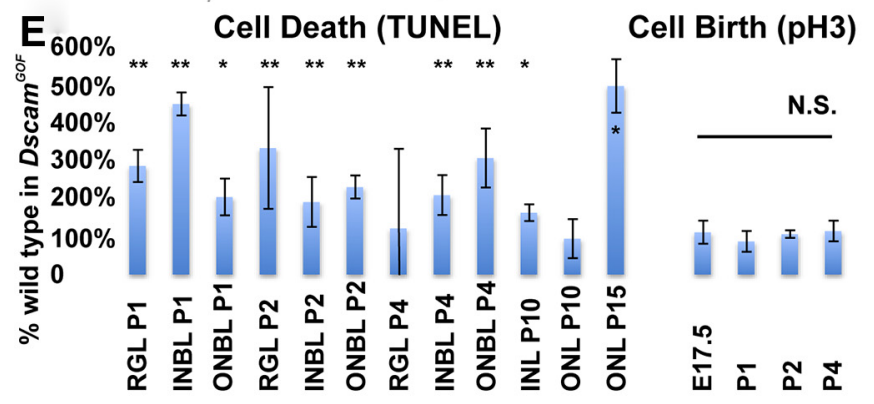

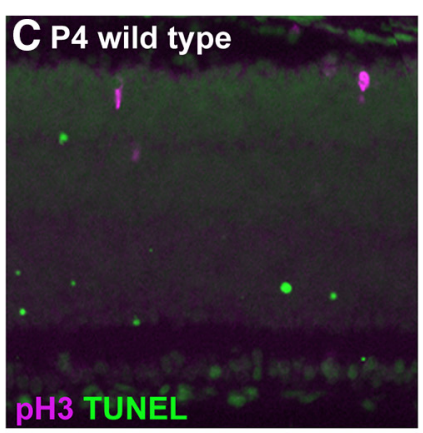
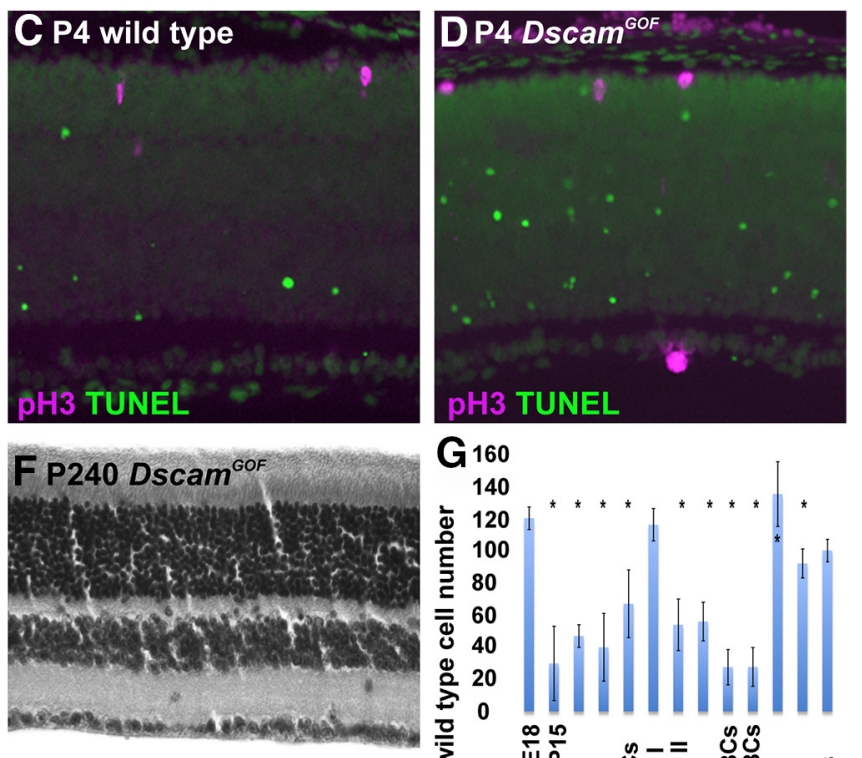

G 160

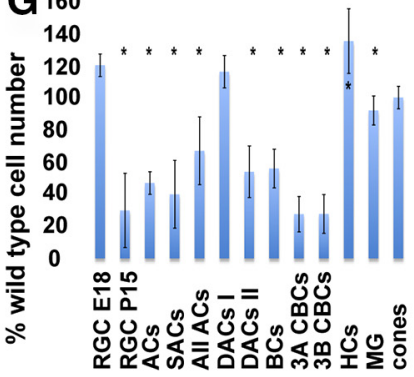

Figure 2. Dscam expression is sufficient to drive cell death. $\boldsymbol{A}, \boldsymbol{B}, \mathrm{H} \& \mathrm{E}$ stained sections of wild-type and Dscam ${ }^{G O F}$ retina. Arrowheads in $\boldsymbol{B}$ indicate location of ectopic rod photoreceptors in the Dscam ${ }^{G O F}$ retina. $C, D, P 4$ sections of wild-type and Dscam ${ }^{G O F}$ retina stained with antibodies to phosphohistone H3 and TUNEL. $\boldsymbol{E}$, Quantification of cell birth and death indicated a significant increase in cell death during development of the Dscam ${ }^{G O F}$ retina compared with wild-type, while no changes in cell birth were detected. The bold line in $\boldsymbol{E}$ is at $100 \%$ wild-type value. $\boldsymbol{F}$, H\&E stained section of P240 Dscam ${ }^{G O F}$ retina. Ectopic photoreceptors are absent. G, Quantification of cell number in the Dscam ${ }^{G O F}$ retina compared with wild-type. Assayed cells of the inner retina, except for type 1 dopaminergic amacrine cells, were significantly depleted in the $D s c a m{ }^{G O F}$ retina. Cone number was unchanged while an increase in $\mathrm{HCs}$ was detected. The bold line in $G$ is at $100 \%$ wild-type value. INBL, inner neuroblast layer; ONBL, outer neuroblast layer; E, embryonic; P, postnatal; BC, bipolar cell; CBC, cone bipolar cell; MG, Müller glia. P15: $\boldsymbol{A}, \boldsymbol{B}$. N $\geq 3$ for all genotypes. Scale bars: (in $\boldsymbol{A}$ ) $\boldsymbol{A}-\boldsymbol{D}$, $100 \mu \mathrm{m} ; \boldsymbol{F}, 120 \mu \mathrm{m}$. Mean $\pm \mathrm{SD} ;{ }^{*} p<0.05,{ }^{* *} p<0.01$ (Student's $t$ test).

drive cell death in the retinal nuclear layers. A significant rescue of cell number comparing the Dscam ${ }^{G O F} / \mathrm{Bax}^{-/-}$retina to the $D$ scam ${ }^{G O F}$ retina was also detected (Fig. $3 I$ ). This indicated that although Dscam can influence cell number independent of Bax, Bax-dependent cell death is the main driver of Dscam-mediated changes in cell number in the $D s c a m^{G O F}$ retina. These results are consistent with findings that DSCAM promotes cell death by acting through BAX and at least one other cell death pathway, and that this additional pathway is sufficient to decrease disorganization by elimination of misplaced cells.

\section{Gain-of-function analysis indicates DSCAM is not sufficient} to drive cell spacing and avoidance in the mouse retina In the second part of this study we set out to test if Dscam can drive avoidance. Dscam is required to prevent cell type-specific adhesion in the dendrites and soma of mouse retinal neurons. Dscam 1 in Drosophila is required to mediate repulsion, in which case the protein actively promotes avoidance of dendrites extending from the same cell (Hughes et al., 2007). To test if mouse DSCAM is sufficient to promote soma and dendrite avoidance, we extended previous spacing analysis comparing $D s c a m^{L O F}$ alleles and wild-type to the Dscam ${ }^{G O F}$ allele. Spacing analysis was performed on starburst amacrine cells (SACs) and horizontal cells (HCs), two retinal neuron types that do not normally express Dscam or its homolog Dscaml1 (de Andrade et al., 2014). We also assayed spacing of type 1 DACs, which express and require Dscam for normal spacing, and AII amacrine cells, which express and require Dscamll for normal spacing. Spatial organization was measured by DRP analysis, NNA, and VD analysis (see Materials and Methods; Rodieck, 1991; Reese and Keeley, 2014).

Spatial organization of SACs was decreased by expression of Dscam, and this decrease correlated with a reduction in cell density (Fig. $4 A, B, E$ ). Rescue of lost cells in the $D_{s c a m}^{G O F} / B_{a x}^{-/-}$ retina eliminated spacing defects as measured by DRP and Voronoi analysis, but not NN analysis (Fig. 4C-E). This indicated that disruption of SAC spatial organization in the $\mathrm{Dscam}^{\mathrm{GOF}}$ retina was largely the result of cell death, and that in the absence of this cell death, spatial organization remained equivalent to or less than wild-type. Spacing of HCs was also analyzed. HCs project neurites that overlap extensively in the wild-type retina, and this overlap was still evident in the $D_{s c a m}{ }^{G O F}$ retina (Fig. $4 F, G$ ). There was also no significant increase in the spatial organization after expression of Dscam in these cells. Instead, we found a slight decrease in the NNRI observed in the $D s c a m^{G O F}$ retina compared with wild-type (Fig. $4 F-H$ ). These results indicate that ectopic expression of Dscam is not sufficient to increase the organization of the spacing of these cell types.

Next we assayed soma placement and dendrite organization of type 1 DACs and AII ACs, which express and require Dscam or Dscaml1, respectively, for normal spacing and dendrite arborization.

We had previously speculated that both Dscam and Dscaml1 were required in the retina to facilitate spacing and avoidance, while their differential expression would allow close interactions, for example, between type 1 DACs and AII ACs (Fuerst et al., 2009). Therefore, we assayed if these interactions continued to form after expression of Dscam in AII ACs. Type 1 DACs continue to make contacts with AII ACs in the Dscam ${ }^{G O F}$ retina, despite the expression of Dscam in these cells in the Dscam ${ }^{G O F}$ retina (Fig. 4I,J, arrows). Extensive overlap of type 1 DAC dendrites also continued in the $D s c a m^{G O F}$ retina (Fig. $4 I, J$ ). This indicates that Dscam expression from the $\mathrm{Dscam}^{G O F}$ transgene is not sufficient to prevent interactions between or within the assayed cell types.

The spacing of wild-type and Dscam ${ }^{G O F}$ type 1 DACs was not significantly different compared with each other, with both being 

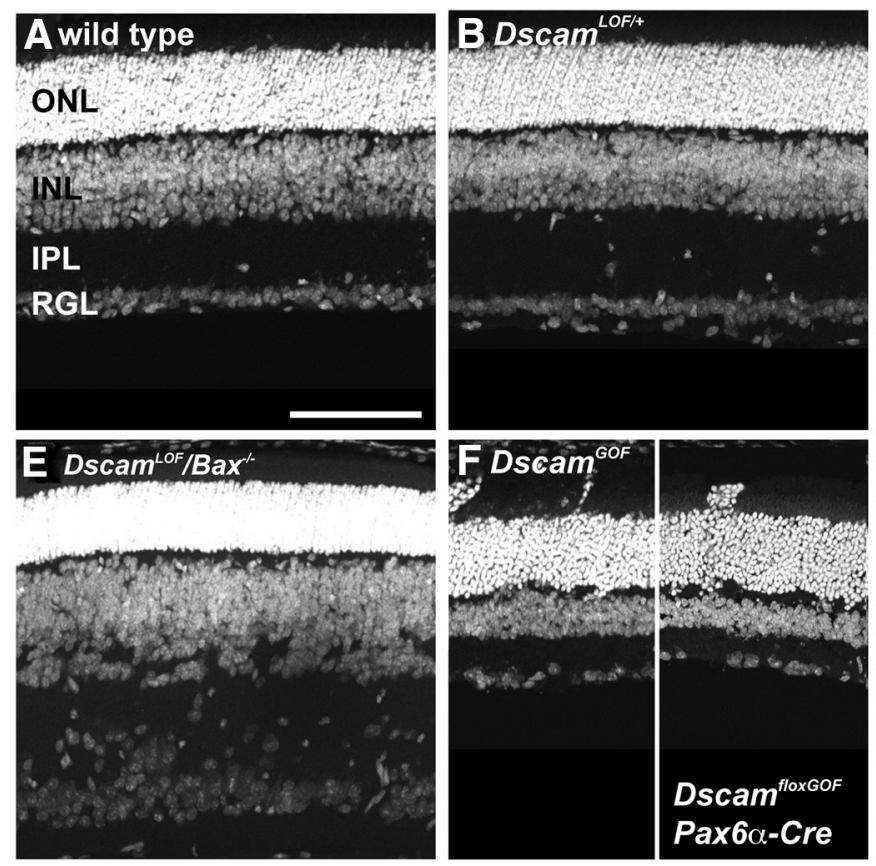

I

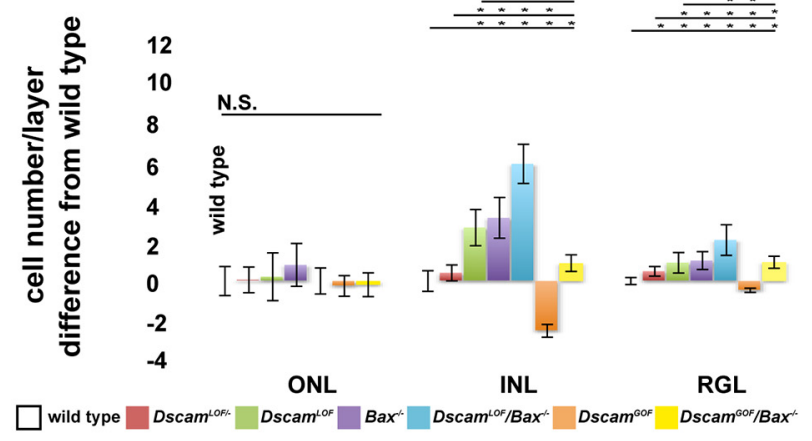

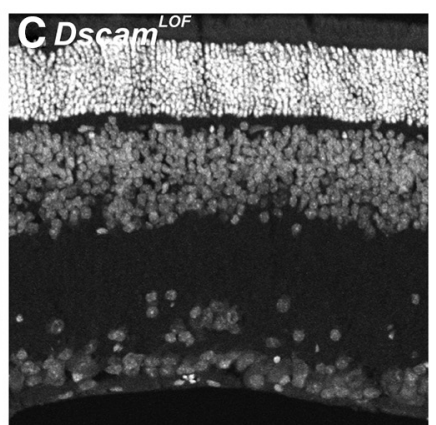
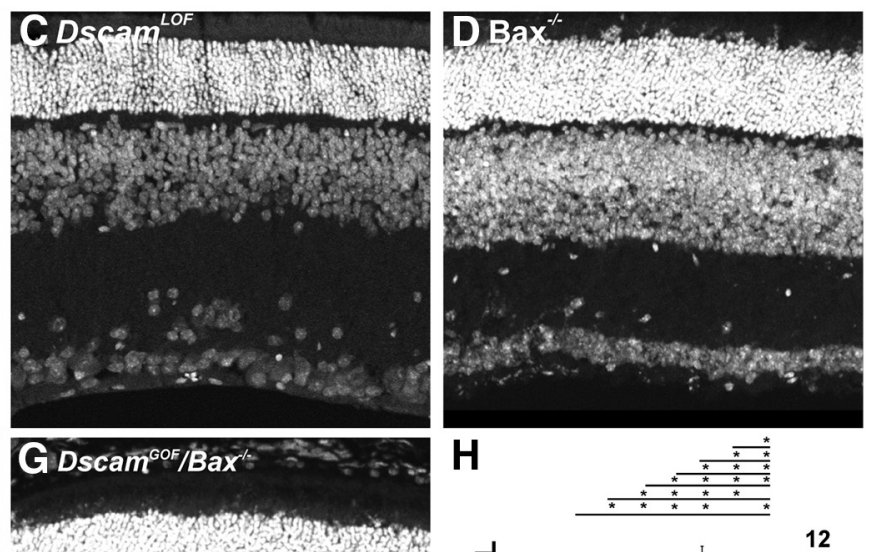

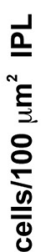

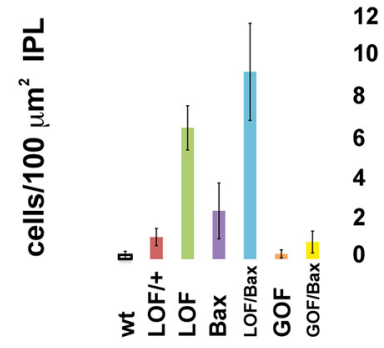

12

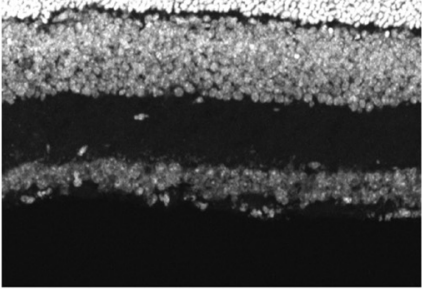

Figure 3. DSCAM regulates cell number in Bax-dependent and -independent manners. $A-G, D R A Q 5$ stained retina sections: wild-type $(\boldsymbol{A}), \operatorname{Dscam}^{\text {LOF/+ }}(\boldsymbol{B}), \operatorname{Dscam}^{\text {LOF }}(\boldsymbol{C}), \operatorname{Bax}^{-/-}(\boldsymbol{D}), \operatorname{Dscam}^{\text {LOF } /}$

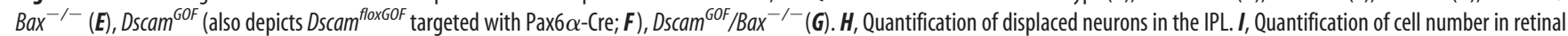
layers. Values are plotted as average difference from wild-type. Wild-type cell number in 0NL: $10.5 \pm 0.08$, INL: $6.64 \pm 0.53, \mathrm{RGL}: 1.17 \pm 0.18$. RGL: retinal ganglion layer. P18 $\mathrm{N}>3$ for all genotypes. Scale bars: (in $\boldsymbol{A}) \boldsymbol{A}-\mathbf{G}, 100 \mu \mathrm{m}$. Mean $\pm S D ;{ }^{*} p \leq 0.01$ (Student's $t$ test).

significantly different from random simulations in the case of nearest neighbor analysis (Fig. $4 M$ ). Interestingly, type 1 DACs require Bax for normal spacing, and elimination of Bax has previously been shown to disrupt spacing of these cells (Keeley et al., 2012). This spacing defect is not rescued by the Dscam ${ }^{G O F}$ transgene and both Bax-deficient genotypes had nearest neighbor regularity values that were not significantly different from random controls (Fig. $4 K-M$ ). We also assayed spacing of AII ACs, which were reduced in number in the Dscam ${ }^{G O F}$ retina (Fig. $2 G$ ). Increased cell death resulted in a decrease in AII AC density (Fig. $4 \mathrm{~N}, \mathrm{O}$ ), but this did not change the spatial organization of this cell type (Fig. 4P).

These results indicate that DSCAM is not sufficient to drive spatial organization, inhibit dendrite crossing within cell types, or prevent cell-to-cell pairing between AII and DACs. Pairing between AII amacrine cells and rod or cone bipolar cells was also intact in the Dscam ${ }^{G O F}$ retina (data not shown). This suggests that Dscam loss-of-function phenotypes do not reflect an active role for mouse DSCAM in repulsion or avoidance in the mouse retina.

\section{DSCAM and dendrite lamination}

In the third part of this study we investigated the influence of DSCAM on dendrite targeting by testing if the protein is necessary and sufficient to direct placement of dendrites. DSCAM has previously been demonstrated to direct neurite placement in the chick retina, in which the protein is concentrated in a single stratum of the IPL, S5 (Yamagata and Sanes, 2008). We therefore tested whether broadly distributed DSCAM in the mouse retina functioned in a similar manner. We then extended this analysis and demonstrated a mechanism by which the widely distributed DSCAM protein is able to act in dendrite targeting.

DSCAM and BAX are necessary to restrict dendrite placement in the mouse inner retina

Similarities between the Bax and Dscam mutant retinas have previously been reported, consistent with both proteins' role in cell death (Keeley et al., 2012; Chen et al., 2013). Because Dscam and Bax regulate cell death in an additive manner (Fig. 3), we hypothesized that compensatory activity of these proteins could promote dendrite lamination by redundantly eliminating cells that 


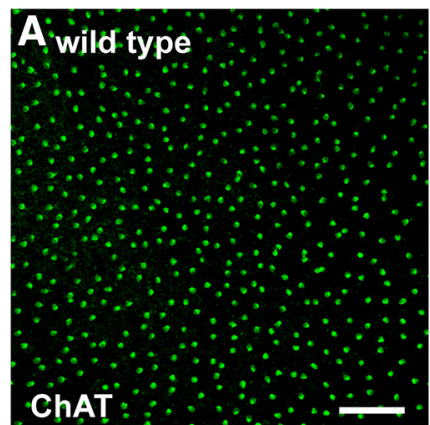

E

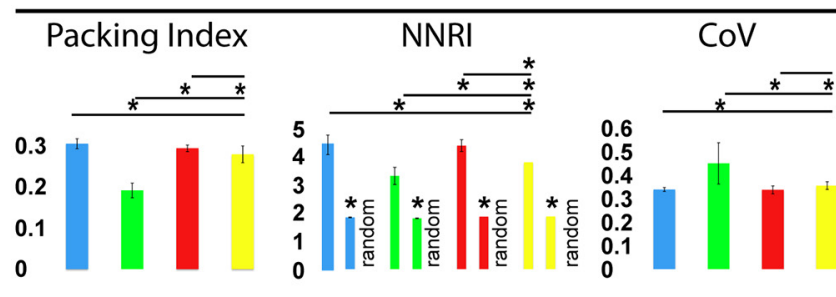

wild type Dscam ${ }^{G O F} \square B^{\prime-}$

$\operatorname{Dscam}^{\text {GOF }}$ Bax $^{\prime-}$

\section{H Horizontal Cells}

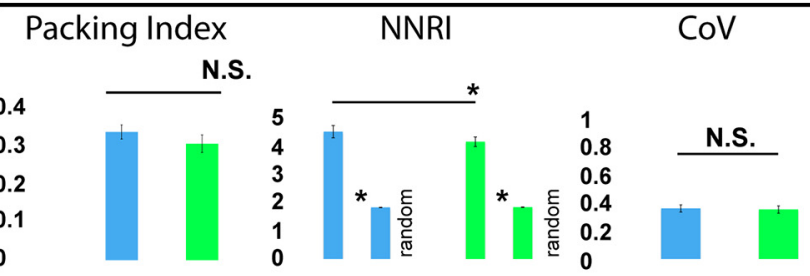

\section{wild type}
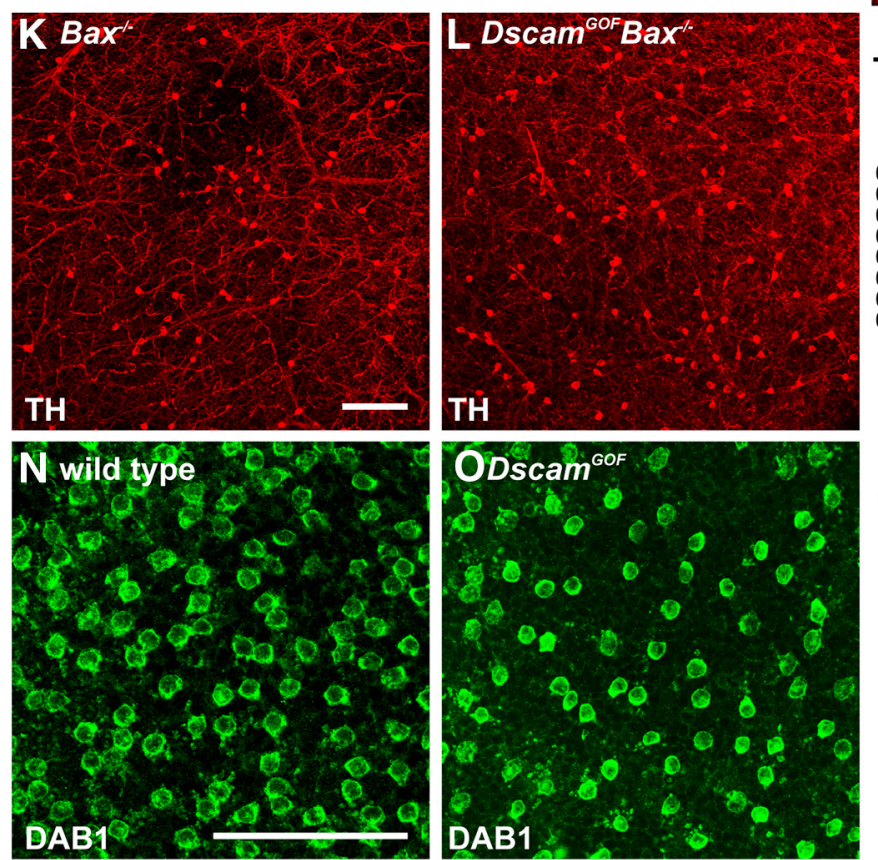
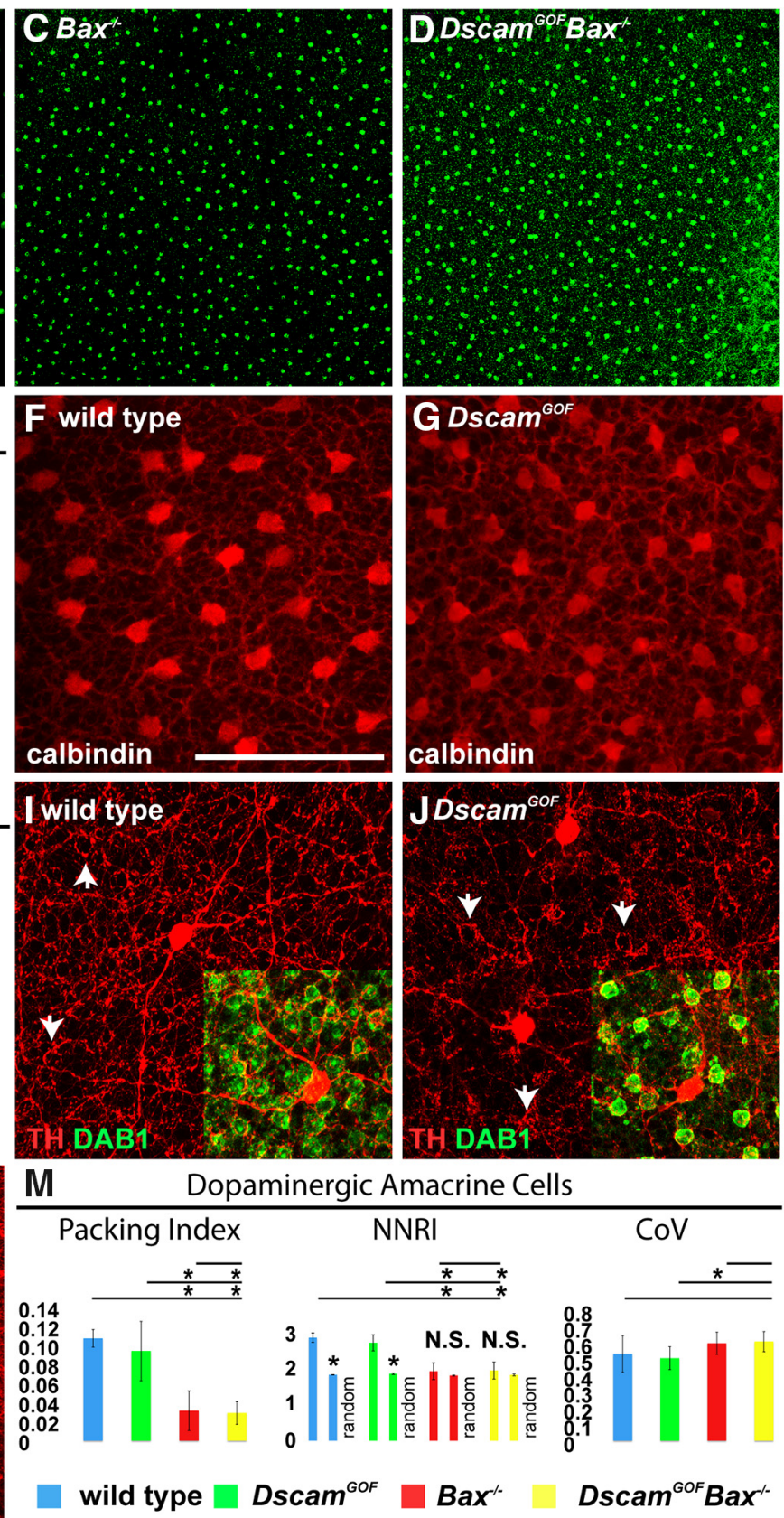

\begin{tabular}{lcc}
$\mathbf{P}$ & All Amacrine Cells & \\
\hline Packing Index & NNRI & CoV
\end{tabular}

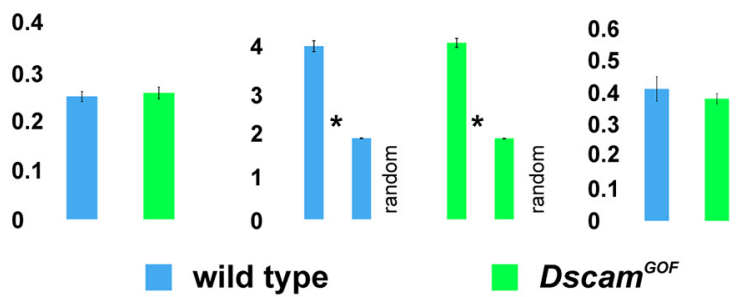

Figure 4. DSCAM is not sufficient to increase spacing or avoidance in the mouse retina. $A-D$, Confocal images of OFF SACs. E, Quantification of DRP (based on packing index), NNA (based on NNRI), and VD analysis (based on CoV) for wild-type, Dscam ${ }^{6 O F}, B a x^{-/-}$, and Dscam ${ }^{6 O F} / B a x^{-/-} S A C s . F, G$, Confocal images of horizontal cells in the wild-type and Dscam ${ }^{6 O F}$ retina. $\boldsymbol{H}$, Quantification of packing index, NNRI, and CoV for wild-type and Dscam ${ }^{G O F}$ horizontal cells. $I, J$, Confocal image of type 1 dopaminergic amacrine and All amacrine cells. Type 1 DACs wrap dendrites around All amacrine cells in wild-type and Dscam ${ }^{6 O F}$ retinas (arrowheads). $\boldsymbol{K}, \boldsymbol{L}$, Confocal image of type $1 \mathrm{DACs}$ in Bax ${ }^{-/-}$and Dscam ${ }^{6 O F} / \mathrm{Bax}^{-/-}$retinas. $\boldsymbol{M}$, Quantification of packing index, NNRI, and CoV for wild-type, Dscam ${ }^{G O F}, B a x^{-\prime-}$, and Dscam ${ }^{G O F} / B a x^{-\prime-}$ type 1 DACs. N, O, Confocal images of All ACs in wild-type and Dscam ${ }^{G O F}$ retinas. P, Quantification of packing index, NNRI, and CoV for wild-type and Dscam ${ }^{G O F}$ All ACs. P28-P42. $N \geq 4$ for all genotypes. Scale bars: (in $\left.\boldsymbol{A}\right) \boldsymbol{A}-\boldsymbol{D}, 100 \mu \mathrm{m}$; (in F) $\boldsymbol{F}, \mathbf{G}, \boldsymbol{I}, \boldsymbol{J}, 100 \mu \mathrm{m}$; (in $\left.\boldsymbol{K}\right) \boldsymbol{K}, \boldsymbol{L}, 100 \mu \mathrm{m}$; (in $\boldsymbol{N}$ ) $\boldsymbol{N}, \mathbf{0}, 100 \mu \mathrm{m}$. Mean \pm SD; ${ }^{*} p \leq 0.05$ (Student'st test). 

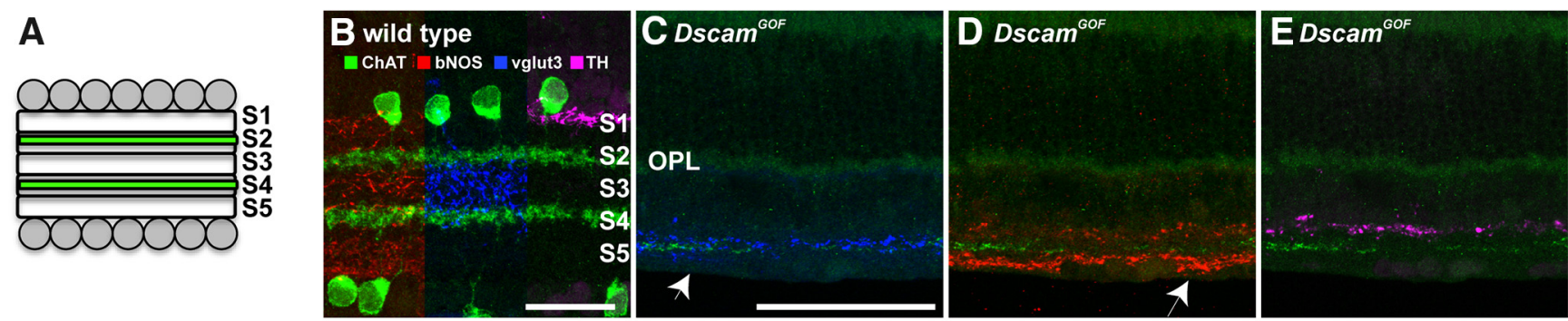

$\mathbf{F}$

percent of neurites stratifying per layer
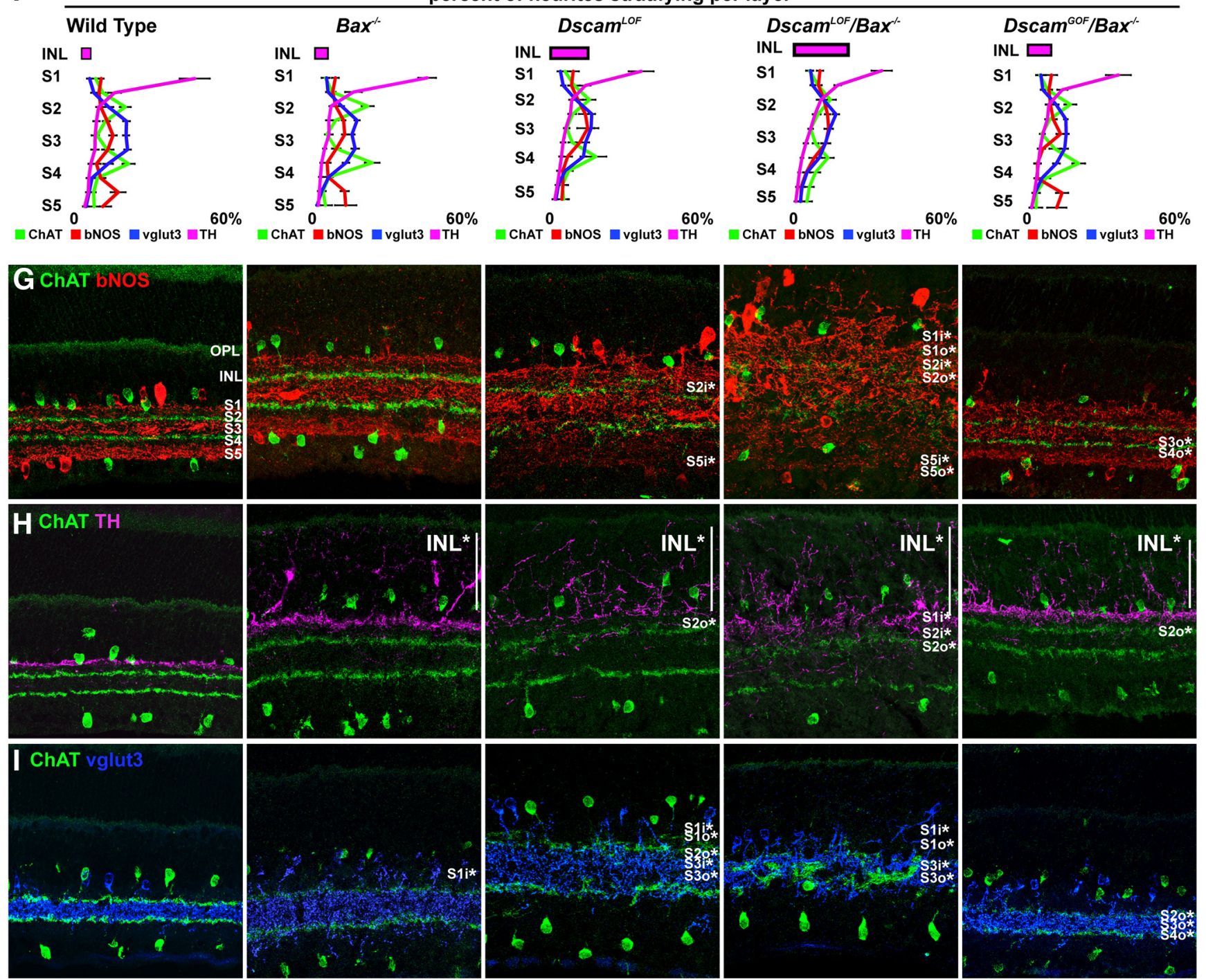

Figure 5. Dscam is necessary for IPL lamination. $\boldsymbol{A}$, Diagram depiction of the retinal IPL divided into five strata, S1-S5. Locations of SAC dendrites are shown in green. $\boldsymbol{B}$, Location of assayed dendrites in the wild-type retina. $C-E$, Lamination of $S A C$, bNOS $+A C$, vglut3 $+A C$, and type 1 DAC dendrites in the Dscam ${ }^{G O F}$ retina. $C$, A single SAC band was observed in most of the Dscam ${ }^{G O F}$ retina (arrow). D, Dendrites projected to regions of the RGL not occupied by cell bodies (arrow). $\boldsymbol{F}$, Plot of percentage dendrites laminating in S1-S5 in the wild-type, Bax ${ }^{-/-}$,Dscam ${ }^{L O F}, D s c a m^{L O F} / B^{2} x^{-/-}$, and $D_{s c a m}{ }^{G O F} / \mathrm{Bax}^{-\prime-}$ genotypes. Each stratum was divided into an inner and outer half for plotting and quantifying percentage lamination. Asterisks in $\mathbf{G}-I$ denote a Mann-Whitney $U$ test $p$ value $<0.01$ compared with wild-type. $\boldsymbol{G}$, Lamination of bNOS + amacrine cell dendrites. $\boldsymbol{H}$, Lamination of type $1 \mathrm{DAC}$ neurites. $\boldsymbol{I}$, Lamination of vglut3 $+\mathrm{AC \text {dendrites. }}$ P18: $N \geq 3$ for all genotypes. Scale bars: $\boldsymbol{B}, 25 \mu \mathrm{m}$; (in $\boldsymbol{C}) \boldsymbol{C}-\boldsymbol{E}, \mathbf{G}-\mathbf{I}, 100 \mu \mathrm{m}$. Mean $\pm \mathrm{SD} ;{ }^{*} p \leq 0.01$ (Mann-Whitney $U$ test).

misproject dendrites. We reasoned that this could generate the weak dendrite lamination phenotypes observed in either mutant retina. To test this hypothesis, we quantified lamination in the IPL based on the convention of dividing the IPL into five stratum established by Ramon y Cajal (1893) (Fig. 5A). Lamination of dendrites spanning these stratum (Fig. $5 B$ ) was quantified, using the ON and OFF SAC dendrite bands to set S2 and S4, with each of the five strata further subdivided into an inner and outer band (for example, S1 inner and S1 outer). The percentage of dendrites in each stratum was measured using software to automate band demarcation based on peak intensity of cholinergic dendrites and the boundaries of the RGL and INL (see Materials and Methods section for more details). These percentages were then used to quantify differences in lamination when comparing across genotypes. This method of quantification precluded analysis of the Dscam $^{G O F}$ genotype because SAC dendrites collapsed into a sin- 
gle band (Fig. 5C, arrow), laminar banding was very inconsistent in these mice, and because dendrites often projected into spaces where RGCs would otherwise be localized (Fig. 5D, arrow). Despite the loss of precisely stratified lamina, dendrites in the $D s c a m^{G O F}$ retina qualitatively projected to the same lamina as their wild-type counterparts (Fig. 5C-E).

Laminar targeting of neurites was plotted and quantified for the wild-type, $\mathrm{Bax}^{-/-}, \mathrm{Dscam}^{\mathrm{LOF}}, \mathrm{Dscam}^{\mathrm{LOF}} / \mathrm{Bax}^{-1-}$, and $D_{\text {scam }}{ }^{G O F} / \mathrm{Bax}^{-1-}$ genotypes (Fig. $5 F$ ). Significant differences in the lamination of bNOS amacrine cells were not detected when comparing wild-type and Bax ${ }^{-1-}$ retinas (Fig. $5 G$ ); however, significant differences in dendrite targeting were detected in two layers of both the $\mathrm{Dscam}^{\mathrm{GOF}} / \mathrm{Bax}^{-1-}$ retina and the Dscam ${ }^{\mathrm{LOF}}$ retina compared with wild-type (Fig. $5 G$ ). Significant differences were also detected in dendrite targeting in 6 of the 10 layers in the

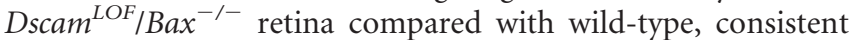
with Bax and Dscam acting to redundantly refine dendrite lamination (Fig. 5G).

Limited disorganization of the lamination of type 1 DAC neurites was observed in the $\mathrm{Bax}^{-/-}, D$ scam $^{L O F}$, and $D$ scam $^{G O F} /$ $B a x^{-1-}$ retinas compared with wild-type, with an increase in the number of neurites (presumably axons) projecting into the INL of these genotypes (Fig. 5H). Distribution of type 1 DAC dendrites was increased in both of the OFF strata (S1 and S2) of the $\mathrm{Dscam}^{\mathrm{LOF}} / \mathrm{Bax}^{-/-}$retina compared with wild-type (Fig. $5 \mathrm{H}$ ).

An increase in the number of ectopic vglut3-positive AC dendrites projecting to a single layer was detected in the $\mathrm{Bax}^{-/-}$ retina compared with wild-type (Fig. 5I). Conversely, a decrease in the number of vglut3-positive AC dendrites laminating at their native targets, along with an increase in the number of ectopic dendrites, was detected in the Dscam ${ }^{L O F}$ and $D s c a m^{L O F} / \mathrm{Bax}^{-/-}$ retinas compared with wild-type (Fig. 5I). A decrease in the number of vglut3-positive AC dendrites laminating at their native targets was detected in the $D s c a m^{G O F} / B^{-1-}$ retina compared with wild-type, but a corresponding increase in ectopic dendrites was not detected.

These results indicate that DSCAM is required for neurite targeting in the mouse retina, an environment where the protein is widely distributed (Fig. $1 F$ ), and that Bax-dependent cell death limits this phenotype in the Dscam ${ }^{L O F}$ retina.

\section{DSCAM is sufficient to retarget outer retinal circuitry}

DSCAM is widely localized in the mouse IPL, and we therefore turned to the OPL to better test if ectopic Dscam expression could retarget neurites. HCs mistargeted neurites into both the IPL and ONL of the Dscam ${ }^{G O F}$ retina: close to one-quarter of HCs projected a bipolar cell-like axon into the IPL of the $D$ scam ${ }^{G O F}$ retina (Fig. 6A,B,J, arrows). The few HC projections contacting the $\mathrm{Dscam}^{\mathrm{GOF}} / \mathrm{Bax}^{-/-}$IPL were located at the thinner peripheral retina, suggesting the depth of the INL could serve as a barrier to formation of these projections (Fig. 6J; data not shown).

HC neurites also projected ectopically into the ONL (Fig. $6 C, D$, arrows). The earliest time point at which this phenotype was detected was P11, but it was evident in all retinas by P13. The dendrites of rod bipolar cells were observed ectopically projecting with $\mathrm{HC}$ neurites into the ONL by P18 (Fig. $6 E$, arrows). Invading neurites terminated in the ONL at puncta of synaptic markers (Fig. $6 F, G$, arrows), and the presence of morphologically normal ribbon synapses within the ONL of the Dscam ${ }^{G O F}$ retina was confirmed by electron microscopy (Fig. $6 \mathrm{H}$, arrow and inset). Projection of $\mathrm{HC}$ neurites occurred at a similar frequency in the absence of Bax, although these neurites terminated closer to the OPL, rather than projecting through gaps in the outer limiting membrane, which were not observed in the $D s \mathrm{sam}^{\mathrm{GOF}} / \mathrm{Bax}^{-/-}$ retina (Fig. 6I; arrowheads; data not shown). Quantification of these results confirmed that the number of $\mathrm{HC}$ projections into the ONL, and the number of synapses within the ONL, were significantly increased in the Dscam ${ }^{G O F}$ allele compared with wild-type (Fig. $6 J)$. In older retinas $(8+$ months), in which the transgene is inactivated in many rods, $\mathrm{HC}$ neurites targeted rods that continued to express Dscam, including those projecting an axon to the OPL (Fig. $6 \mathrm{~K}$ ). These results indicate that ectopic expression of Dscam results in retargeting of retinal neurites.

\section{DSCAM promotes IPL dendrite lamination by restricting dendrite target choice}

To identify potential developmental mechanisms by which DSCAM promotes dendrite targeting in ACs, we used GFPtagged type 2 DACs (Knop et al., 2011) because this cell type had uniform and reproducible lamination defects in the Dscam mutant retina. Type 2 DACs normally target dendrites exclusively to S3 of the IPL (Fig. 7A; Bruggen et al., 2014). In the Dscam heterozygous and homozygous mutant retina, these cells target dendrites to both $\mathrm{S} 1$ and $\mathrm{S} 3$ (Fig. $7 \mathrm{~B}, \mathrm{C}$, arrows). DSCAM protein was produced by type $2 \mathrm{DACs}$ and was localized to the dendrite tips of these cells in vitro, consistent with it functioning to regulate dendrite lamination in this cell population (Fig. 7D).

We confirmed that the dendrites projecting to $\mathrm{S} 1$ are distinct from type 1 DACs by immunoreactivity with $\mathrm{TH}$, which stains type 1, but not type 2, DACs. Type 1 DACs project dendrites to S1 in the wild-type retina (Fig. 7E), whereas we observed an absence of type 2 DAC dendrites in S1 of the wild-type retina (Fig. $7 F, G$ ). In the Dscam ${ }^{L O F /+}$ retina, type 2 DACs project dendrites to both S1 and S3 (Fig. 7H, arrow). Confocal analysis of layer S1 of the $\mathrm{Dscam}^{\mathrm{LOF/+}}$ retina confirmed that these bright GFP-positive dendrites lack TH (Fig. 7I,J, arrows).

Cell density was assayed to determine whether type 2 DACs that projected neurites were simply cells that did not undergo cell death in the $\mathrm{Dscam}^{\mathrm{LOF} /+}$ retina. Type 2 DAC cell number was not significantly changed when comparing $D_{s c a m}{ }^{L O F /+}$ retinas to wild-type retinas (Fig. 7K). A significant increase in cell number was observed in the $D$ scam ${ }^{L O F}$ retina compared with either wildtype or $D$ scam ${ }^{L O F /+}$ retinas (Fig. $7 K$ ). Spacing of type 2 DACs was also assayed, to determine whether their cell bodies were abnormally spaced in the absence of Dscam. Spacing of type 2 DACs was dependent on Dscam in a dose-dependent manner, with significantly lower NNRI and DRP packing index values detected as Dscam dosage decreased (Fig. $7 L, M$ ).

These data demonstrate that type 2 DACs require Dscam for regulation of cell number, spacing, and lamination. Because the layers (S1 and S3) are sufficiently separated and the heterozygous Dscam mutant pups do not have a growth defect, we could for the first time readily examine the influence of Dscam dosage on the development of lamination defects in the mouse retina.

First we assayed development of type 2 DACs in wild-type and $D s c a m^{L O F /+}$ retinas. A similar number of wild-type and $\mathrm{Dscam}^{\mathrm{LOF} /+}$ type $2 \mathrm{DACs}$ projected dendrites into $\mathrm{S} 1$ at early time points, indicating that these cells have a normal tendency to ramify dendrites in both $\mathrm{S} 1$ and S3 (Fig. $8 A, B$, arrows, $H$, P3). A significant increase in cells that project dendrites into $S 1$ was observed in the $\mathrm{Dscam}^{\mathrm{LOF} /+}$ retina compared with wild-type by P5, and these cells accounted for the majority of type 2 DACs by this age (Fig. $8 C, D$, arrows, $H, P 5)$. By P10 GFP fluorescence in this cell type was sufficiently brighter than GFP produced by other cells in the $D s c a m^{G O F}$ retina, allowing us to assay the effect of Dscam overexpression on laminar targeting of type 2 DACs. A 

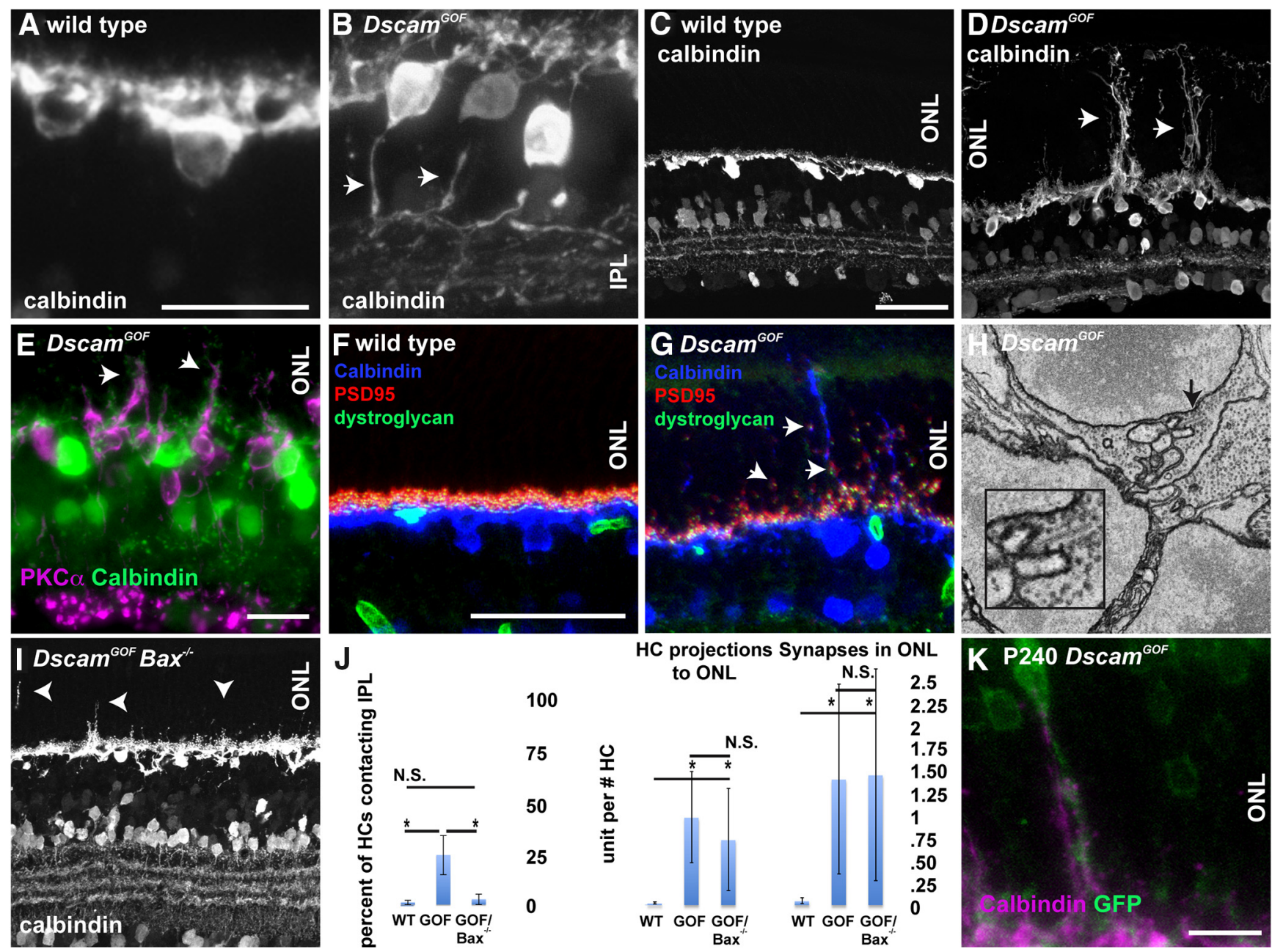

HC projections Synapses in ONL
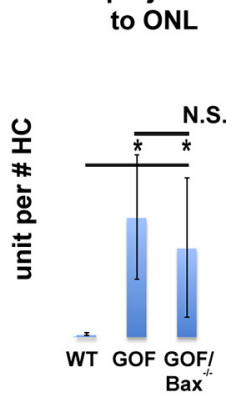

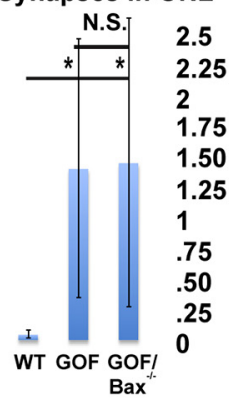

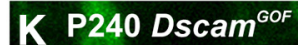

Figure 6. DSCAM is sufficient to retarget neurites in the outer retina. $A-D, H C$ s in the wild-type and $D$ scam ${ }^{G O F}$ retina. $A, B, N$ Nearly $25 \%$ of $D$ scam ${ }^{G O F}$ HCs projected a neurite through the INL to the IPL ( $\boldsymbol{B}$, arrows). $\boldsymbol{C}, \boldsymbol{D}, \mathrm{HC}$ s projected neurites into the $0 \mathrm{NL}$ in the Dscam ${ }^{G O F}$ retina ( $\boldsymbol{D}$, arrows). $\boldsymbol{E}$, Bipolar cell dendrites projected into the $0 \mathrm{NL}$ after $\mathrm{HC}$ neurites $(\boldsymbol{E}$, arrows). $\boldsymbol{F}, \boldsymbol{G}$, The synaptic markers PSD-95 and dystroglycan were localized to the tips of HC neurites in the Dscam ${ }^{G O F}$ ONL ( $G$, arrows). $\boldsymbol{H}$, Ribbon synapses were observed in the Dscam ${ }^{G O F}$ ONL by electron microscopy. $\boldsymbol{I}, \mathrm{HC}$ neurites

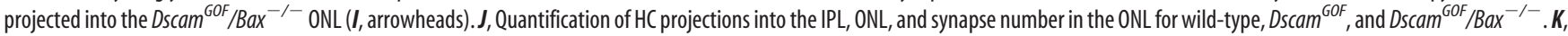
$\mathrm{HC}$ neurites projecting into the Dscam ${ }^{G O F}$ ONL-targeted Dscam-expressing rods, including those that projected an axon to the $0 \mathrm{PL}$. P15: $\boldsymbol{A}-\mathbf{G} ; \mathrm{P} 42: \boldsymbol{H} ; \mathrm{P} 18: \boldsymbol{I}, \mathbf{J} ; \mathrm{P} 240: \boldsymbol{K}$. N $\geq 4$ for all assays/genotypes. Scale bars: (in $\boldsymbol{A}) \boldsymbol{A}, \boldsymbol{B}, 25 \mu \mathrm{m}$; (in $\boldsymbol{C}$ ) $\boldsymbol{C}, \boldsymbol{D}, \boldsymbol{I}, 50 \mu \mathrm{m} ; \boldsymbol{E}, 10 \mu \mathrm{m}$; (in $\boldsymbol{F}) \boldsymbol{F}, \boldsymbol{G}, 50 \mu \mathrm{m} ; \boldsymbol{K}, 10 \mu \mathrm{m} ; \boldsymbol{H}, 3.5 \mu \mathrm{m}^{2}$. Mean \pm SD; ${ }^{*} p \leq 0.05$ (Student's t test).

significant decrease in the number of type 2 DACs that project dendrites into $S 1$ was observed in the $D s c a m^{G O F}$ retina compared with wild-type or the $D s c a m^{L O F /+}$ retina, while significantly more neurites targeted $\mathrm{S} 1$ in the $\mathrm{Dscam}^{\mathrm{LOF} /+}$ retina compared with wild-type (Fig. $8 E-G$, arrows, $H, P 10$ ). These results indicate that Dscam promotes refinement of type 2 DACs during development by preventing stabilization of dendrites and that Dscam expression levels positively correlated with the degree of S1 dendrite pruning.

Extensive remodeling of pyramidal cell dendrites is observed in the Dscam-deficient cortex over extended postnatal periods (Maynard and Stein, 2012), and we were curious if a similar remodeling would occur with age in the type 2 DACs. Dendrites that projected into $\mathrm{S} 1$ of the $\mathrm{Dscam}^{\mathrm{LOF} /+}$ retina were stable and observed in the majority of cells after eye opening and visual function and at all subsequent time points assayed (up to 6 months; data not shown; Fig. $8 H$ ). Analysis of whole retinas indicated that by P15, wild-type dendrites localized in S1 invariably dove into S3 after projecting a short distance in S1, whereas $\mathrm{Dscam}^{\mathrm{LOF} /+}$ dendrites terminated in S1 (data not shown). Many type 2 DACs also projected dendrites into $\mathrm{S} 1$ in the $\mathrm{Bax}^{-/-}$retina
(Fig. $8 H$ ). A large increase in the number of these cells was observed in the $B a x^{-/-}$retina (P15: $B a x^{-/-} 488 \pm 94$ cells $/ \mathrm{mm}^{2}$ vs wild-type sibling controls $181 \pm 27$ cells $/ \mathrm{mm}^{2}$; $t$ test $p<0.01$ ), consistent with these being cells that failed to undergo developmental cell death.

These data address the question of how the broadly distributed DSCAM protein in the mouse IPL can promote the specificity of dendrite lamination and indicate that DSCAM promotes dendrite targeting in the mouse IPL by selectively inhibiting stability of exploring dendrites.

\section{Function follows form}

ERGs were performed to test if the morphological abnormalities observed in the Dscam gain- and loss-of-function retinas influenced the synaptic activity of the retina. $D s c a m^{G O F}$ mice displayed significant reductions in the dark-adapted, rod-driven a-wave amplitude; the b-wave amplitudes; and the light-adapted conemediated response at 4 months of age (Fig. $9 A-E$ ). The normalized b-wave of $D_{\text {scam }}{ }^{G O F}$ mice (0.455) is more severely reduced than the decrease in the amplitude of the a-wave (0.723), demonstrating that the reduction in the b-wave is not secondary to a 

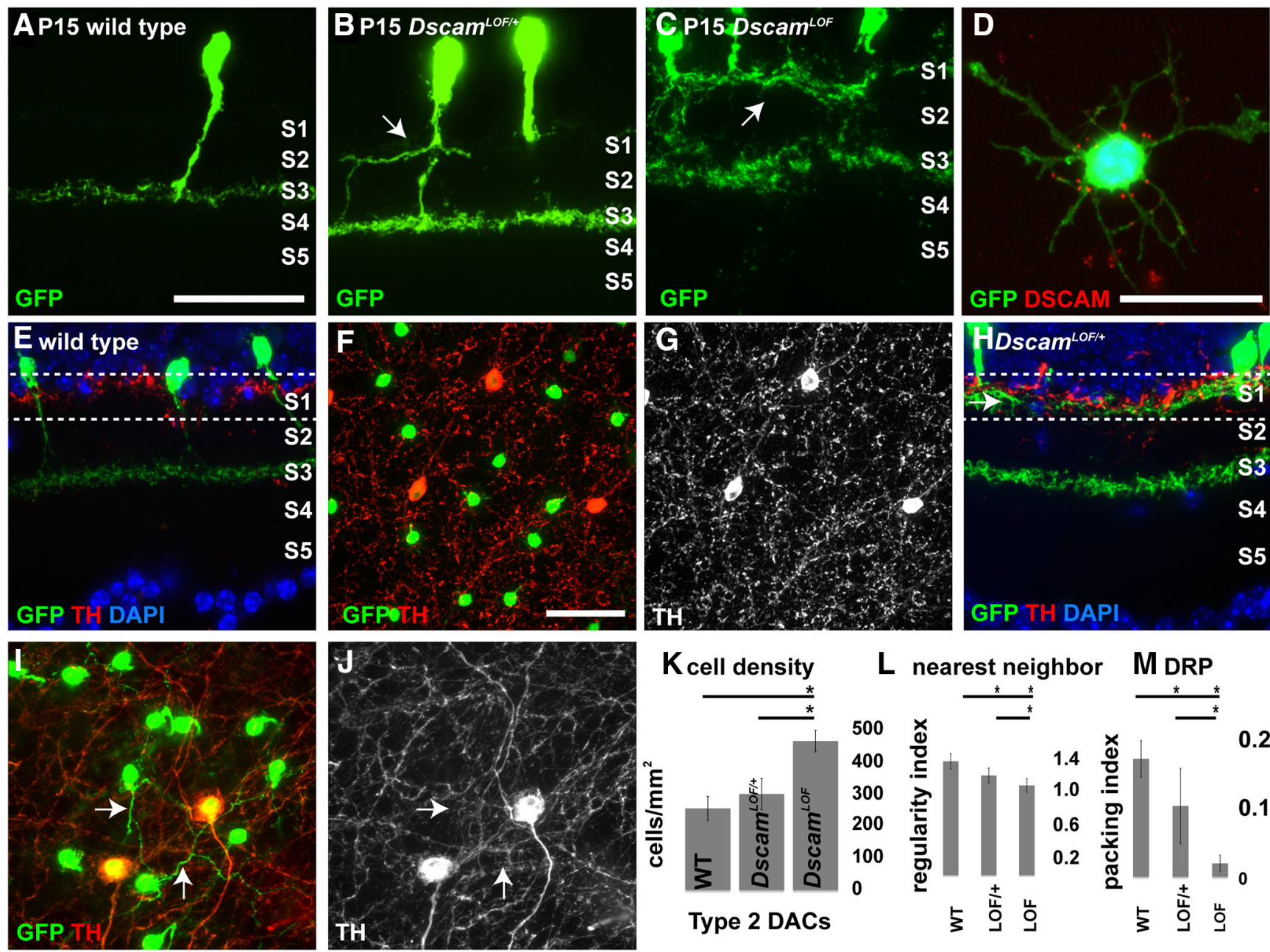

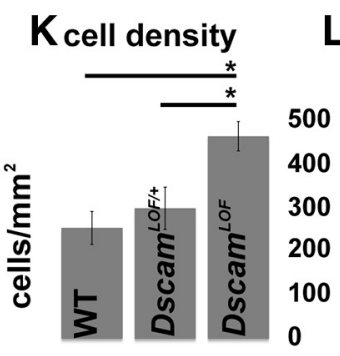

Type 2 DACs
$\mathbf{L}$ nearest neighbor

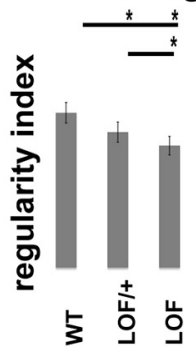

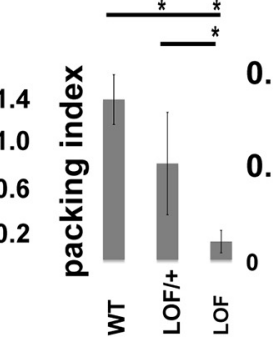

Figure 7. Type 2 DAC lamination defects are dependent on Dscam dosage. $\boldsymbol{A}-\boldsymbol{C}$, Type 2 DACs labeled with a GFP-expressing transgene. $\boldsymbol{A}$, Type 2 DACs project dendrites to S3 at P15 in the wild-type retina. $B, C$, Type 2 DACs in the Dscam ${ }^{L O F /+}$ or Dscam ${ }^{L O F}$ retina project dendrites to both S1 and S3 (arrows). D, Type 2 DAC in vitro labeled with an antibody to DSCAM. DSCAM protein was localized to dendrites. $\boldsymbol{E}$, Section of wild-type retina with type 1 and 2 DACs labeled (type $1=\operatorname{dim}$ GFP and TH, type $2=$ GFP only). Dotted lines show the depth of confocal images in $\boldsymbol{F}$ and $\boldsymbol{G}$. $\boldsymbol{F}$, $\boldsymbol{G}$ Type 1 and 2 DACs in a confocal section of layer $S 1$ of the wild-type retina. Dendrites in S1 are those of type 1 DACs. $\boldsymbol{H}_{\text {, Section of Dscam }}^{\text {LOF/+ }}$ retina with type 1 and 2 DACs labeled (type $1=$ dim GFP and TH, type $2=$ GFP only). Dotted lines show the depth of confocal images in I and J. Dendrites of type 2 DACs laminate in S1 of the Dscam ${ }^{\text {LOF/+ }}$ retina as evidenced by the lack of TH staining in bright GFP-positive dendrites (arrows). $K$, Quantification of type 2 DAC cell number in the wild-type, Dscam ${ }^{L O F /+}$, and Dscam ${ }^{L O F}$ retinas. Cell density was significantly increased in the Dscam ${ }^{2 O F}$ retina compared with wild-type and Dscam ${ }^{L O F /+}$ retina. Significant differences were not detected comparing the wild-type and Dscam ${ }^{\text {LOF/+ }}$ retina. $L$, Nearest neighbor (NN) analysis of type 2 DACs. NN regularity significantly decreased as Dscam dosage decreased. $\boldsymbol{M}, \mathrm{DRP}$ analysis of type $2 \mathrm{DACs}$. Packing index values significantly decreased as $D$ scam dosage decreased. P15: $N \geq 10: \boldsymbol{A}-\boldsymbol{C}, \boldsymbol{E}, \boldsymbol{H} ; \boldsymbol{N}=$ 3: $\boldsymbol{D} ; \boldsymbol{N} \geq 4: \boldsymbol{F}, \boldsymbol{G}, \boldsymbol{I}, \boldsymbol{J}$. Scale bars: (in $\boldsymbol{A}) \boldsymbol{A}-\boldsymbol{C}, \boldsymbol{E}, \boldsymbol{H}, 50 \mu \mathrm{m} ; \boldsymbol{D}, 25 \mu \mathrm{m}$; (in $\boldsymbol{F}) \boldsymbol{F}, \boldsymbol{G}, \boldsymbol{I}, \boldsymbol{J}, 50 \mu \mathrm{m}$. Mean \pm SD; ${ }^{*} p \leq 0.05$ (Student's $t$ test).

decreased a-wave. These findings persist at 6 months, with the normalized b-wave amplitude more severely affected than the a-wave amplitude (a-wave, 0.579; b-wave, 0.289; data not shown). At this point we cannot determine whether a decrease in the b-wave is entirely due to a reduction in bipolar cell number, or if synaptic transmission at the rod spherule is also disrupted. Therefore misregulation of Dscam expression alters both the morphology and physiology of the retina.

\section{Discussion}

The major findings of this study are as follows: (1) DSCAM is sufficient to drive cell death and can regulate cell death independent of Bax, (2) dendrite avoidance defects in the Dscam loss-offunction retina do not reflect a role for DSCAM in repulsion analogous to Drosophila Dscam1, and (3) DSCAM is necessary and sufficient to target neurites, even in systems in which the protein is widely distributed such as the mouse IPL, and that it does so by restricting the locations in which exploring dendrites are able to stabilize.

\section{Dscam drives cell death in the retina}

Gain- and loss-of-function results support a role for Dscam as a critical driver of developmental cell death in the developing mouse retina. Previous analysis of the loss-of-function Dscam brain suggested that this might hold true for other parts of the nervous system; for example, a small increase in the size of the Dscam-null hindbrain has been reported (Amano et al., 2009). Further analysis of the Dscam mutant brain identified an overall increase in brain/body size ratio in mutant mice, and regions of the brain that were increased or decreased in size were identified, but changes to cell death or birth were not identified in the cortex, which was the focus of the study (Maynard and Stein, 2012). Changes in brain size could therefore be the result of reduced or increased neurite elaboration and changes to the visual system. Further work assisted by conditional gain- and loss-of-function analysis will help clarify the extent to which Dscam can drive cell death outside of the retina. Identifying the Bax-independent mechanism by which DSCAM drives cell death in the inner retina 

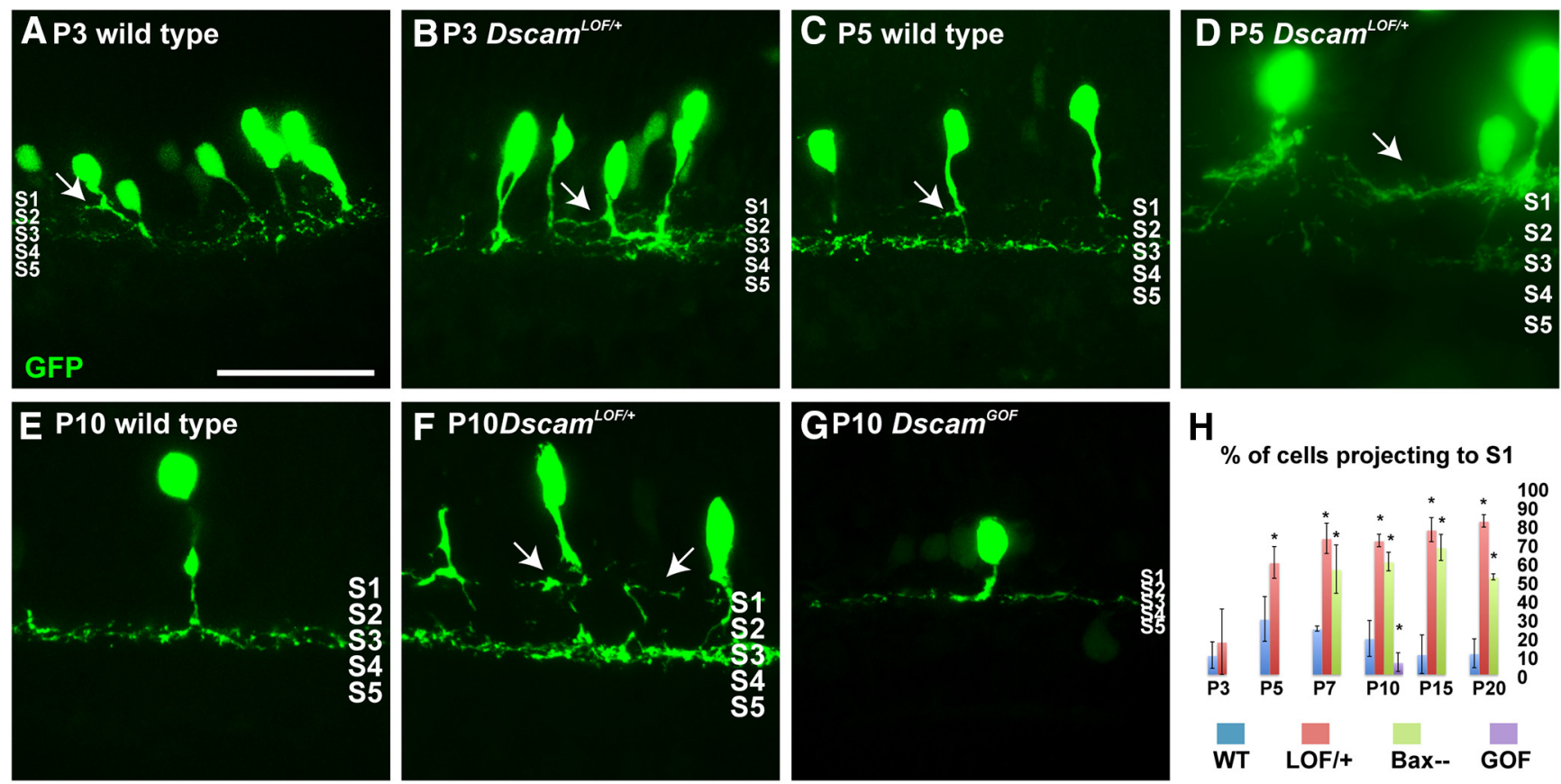

Figure 8. DSCAM prevents stabilization of exploring dendrites. $A-G$, Type 2 DACS. $A, B$, Type 2 DACs in the wild-type and Dscam ${ }^{L O F /+}$ retina at P3. A statistically similar number of type $2 \mathrm{DACs}$ project into $\mathrm{S} 1$ comparing the wild-type and Dscam ${ }^{\mathrm{LOF} /+}$ retina (arrows; $\boldsymbol{H}, \mathrm{P3}$ ). $\boldsymbol{C}, \boldsymbol{D}$, Type $2 \mathrm{DACs}$ in the wild-type and Dscam ${ }^{\text {LOF/+ }}$ retina at P5. A statistically significant increase in the number of type $2 \mathrm{DACs}$ that project dendrites into $\mathrm{S} 1$ of the $\mathrm{Dscam}^{\mathrm{LOF/+}}$ retina was observed as compared with controls (arrows; $\boldsymbol{H}, \mathrm{P} 5$ ). $\boldsymbol{E}-\boldsymbol{G}$, Type $2 \mathrm{DACs}$ in the wild-type, Dscam ${ }^{L O F /+}$, and Dscam ${ }^{G O F}$ retina at P10. A statistically significant increase in the number of type 2 DACs project dendrites into $S 1$ of the Dscam ${ }^{L O F /+}$ retina was observed compared with wild-type or Dscam ${ }^{G O F}$ cells $\left(\boldsymbol{F}\right.$, arrows). A statistically significant decrease in the number of type 2 DACs projecting dendrites into $S 1$ was observed in the Dscam ${ }^{6 O F /+}$ retina compared with wild-type or Dscam ${ }^{L O F /+}$ cells $(\boldsymbol{H}, \mathrm{P} 10)$. $\boldsymbol{H}$, Quantification of type 2 DAC projections into S1. $N \geq 3$ : P3, P5, P10, and P15; $N=2$ WT and Bax ${ }^{-1-}$ P7 and P20. Scale bars: (in $\boldsymbol{A}$ ) $\boldsymbol{A}-\boldsymbol{G}, 50$ $\mu \mathrm{m}$. Mean $\pm S \mathrm{SD}{ }^{*} p \leq 0.05$ (Student's $t$ test).

A

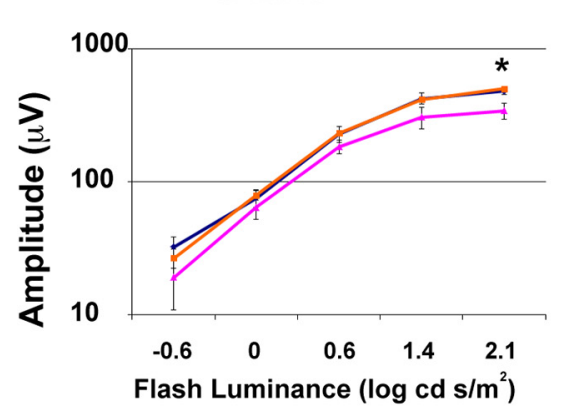

B

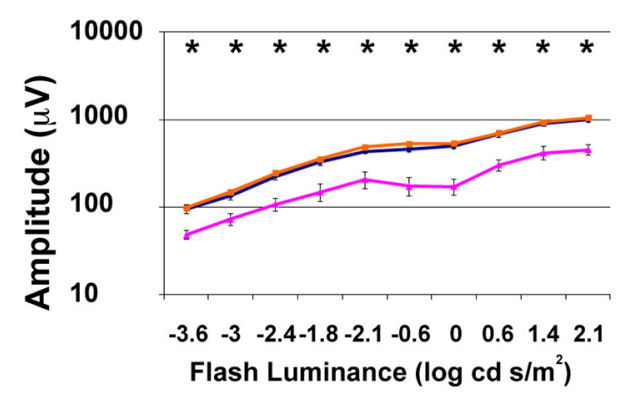

C

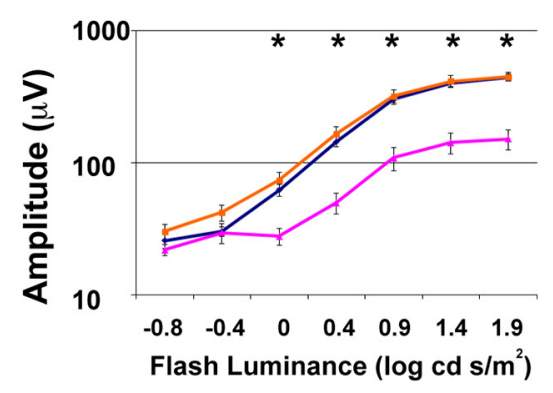

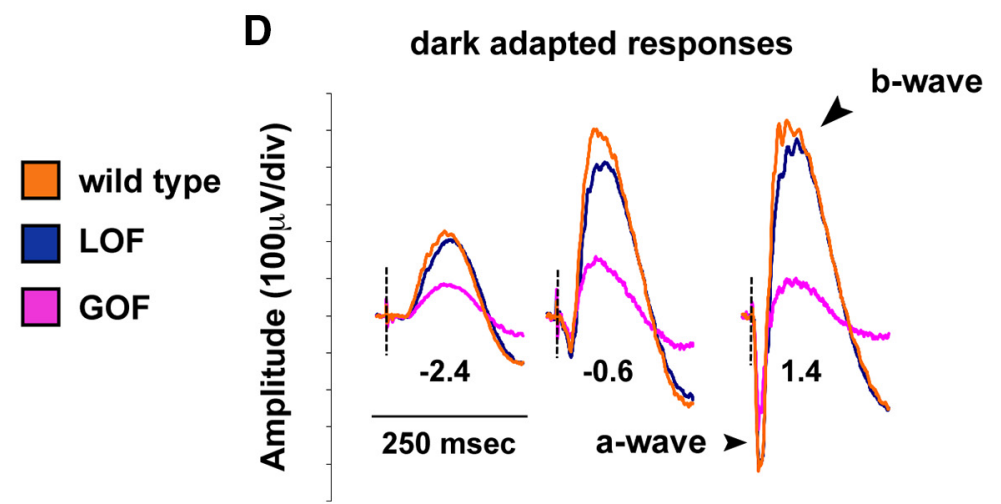

E

Figure 9. Dscam overexpression disrupts physiology of outer plexiform layer circuitry. $A-E$, Light-and dark-adapted physiology of the wild-type, Dscam ${ }^{L O F}$, and Dscam ${ }^{6 O F}$ retina measured by ERG. $A, D$, The a-wave of $D s c a m^{G O F}$ mice was significantly reduced compared with wild-type or $D s c a m^{L O F}$ mice. $B, D$, The b-wave of $D s c a{ }^{G O F}$ mice was significantly reduced compared with wild-type or $D$ scam ${ }^{L O F}$ mice. C, $E$, The photopic wave of $D s c a m^{G O F}$ mice was significantly reduced compared with wild-type or Dscam ${ }^{L O F}$ mice. $N=6$ for all genotypes. Mean $\pm S D ;{ }^{*} p \leq 0.01$ (Student's $t$ test). 
will also be an important line of future research. The Bax homolog Bakl is an excellent target for further analysis (Hahn et al., 2003).

\section{DSCAM and dendrite avoidance}

Previous studies have identified roles for vertebrate Dscam in both adhesion and avoidance in the developing vertebrate nervous system. Loss of Dscam or Dscamll function results in a soma and dendrite-clustering phenotype that superficially resembles a similar dendrite self-avoidance phenotype observed in Drosophila Dscam1 mutants (Zhu et al., 2006; Hattori et al., 2007; Matthews et al., 2007). Dscam 1 has been shown to actively drive avoidance through repulsion, which limits dendrites of a given cell from crossing other dendrites originating from the same cell (Hughes et al., 2007). Several differences between the anatomy of the systems analyzed in mouse and Drosophila suggest that these processes might not be analogous. First, mouse Dscam is not extensively alternatively spliced, and functional alternative splice forms have not been reported (Yamakawa et al., 1998). Second, analyzed cell types arborizing dendrites in the mouse retina overlap extensively (Keeley and Reese, 2010), and do not approximate the tiling observed, for example, in type IV DA cells in Drosophila (Soba et al., 2007). Third, many different cell types in the mouse inner retina require Dscam to prevent a cell type-specific avoidance that occurs in its absence, suggesting that this phenotype is the result of other cell type-specific adhesion molecules.

In this study, we tested if Dscam is sufficient to induce avoidance or increase regularity of spacing. We found that its overexpression in cells that express either Dscam or Dscaml1, or its ectopic expression in SACs or HCs, all failed to increase spatial organization as assayed (Fig. 4). These results suggest that the role of mouse Dscam may be better reflected by some of the other Drosophila Dscams or phenotypes (Millard et al., 2010; Hutchinson et al., 2014), with the role of Drosophila Dscam1 in mouse likely provided by other molecules, such as the $\gamma$-protocadherins (Lefebvre et al., 2008, 2012).

\section{DSCAM and dendrite targeting}

In addition to being required for avoidance, $D$ scam has also been implicated in providing neurite-targeting cues during lamination of the chick retina (Yamagata and Sanes, 2008). In previous studies, limited dendrite lamination defects were identified in the mouse retina and we show here that this limited defect is partially explained by Bax-dependent cell death that occurs in the Dscamdeficient retina. Gain-of-function studies did indicate that Dscam expression in the outer retina is sufficient to retarget neurites to both the IPL and ONL. Projection of HC neurites into the ONL is observed in several other models, including the aging retina (Liets et al., 2006; Samuel et al., 2011, 2014), plexin and semaphorindeficient retinas (Matsuoka et al., 2012), and retinas in which physiology is disrupted (Claes et al., 2004; Michalakis et al., 2013). The targeting of individual Dscam-expressing rods by HC neurites in the older Dscam ${ }^{G O F}$ retina suggests that the DSCAM protein is sufficient to attract $\mathrm{HC}$ neurites, but we cannot rule out that individual rods have defective synaptic structure and act to recruit input secondary to this.

\section{Dscam and dendrite refinement}

By analyzing the role of DSCAM in dendrite lamination during development, we identified a novel role for DSCAM in restricting the location that retinal dendrites can stabilize. Mature type 2 DAC cells normally project dendrites to a single layer of the IPL
(Bruggen et al., 2014), but as Dscam dosage decreases they adopted a bistratified morphology. Further analysis found that the dendrites of these cells, like those of other retinal neurons (Huckfeldt et al., 2009; Reese and Keeley, 2014), initially project dendrites that later retract. A limited and nonsignificant increase in cell number in the Dscam heterozygous mutant retina indicated that deficiency in cell death is not sufficient to explain the presence of bistratified type 2 DACs, which account for the majority of these cells in the $\mathrm{Dscam}^{\mathrm{LOF/+}}$ retina. Gain-of-function analysis identified a precocious refinement of type 2 DACs, consistent with loss-of-function results.

A simple model for how DSCAM mediates phenotypes in the mouse retina could involve the destabilization of dendrites. DSCAM-mediated signaling has been demonstrated to activate the tyrosine receptor kinases Fyn and Fyk, and induce collapse of growth cones in axon outgrowth assays (Purohit et al., 2012). A model wherein DSCAM signaling results in destabilization and retraction of weakly adhesive contacts would explain both the gain- and loss-of-function phenotypes described in the mouse retina. In this model, adhesive tendencies between cells of the same type are strengthened and cause ectopic clumping in the Dscam-deficient retina, while weak connections are not eliminated, resulting in a lack of refinement and the observation of non-native dendrite projections. Increasing or decreasing dendrite stability could then influence the likelihood that cells would form connections and survive developmental cell death. While we propose that our results are most consistent with DSCAMweakening adhesion, consistent with the ectopic clumping observed in the Dscam-deficient retina, we cannot rule out the possibility that DSCAM-DSCAM interactions strengthen a subset of interactions, and therefore cause weaker connections to retract. In either case, the end result on a cellular level would be the same, with weaker connections eliminated. The necessity of a system to eliminate misplaced connections is evidenced by studies investigating how retinal circuitry is established, particularly given the broad overlap of adhesive molecules such as cadherins (Duan et al., 2014) and Ig-domain proteins such as contactins (Yamagata and Sanes, 2012).

\section{Dscam and Down syndrome}

An important human health implication of this research is in understanding the role of Dscam in DS, the most common form of genetic mental retardation. DS is caused by overexpression of genes on chromosome 21, including a subset of 33 genes in a minimal critical region that encompasses Dscam, which are sufficient to give rise to a diagnosis of DS (Lejeune et al., 1959; Rahmani et al., 1990). A hallmark of the developing DS brain is hypocellularity in the cortex, cerebellum, and other regions of the brain, accompanied by changes to dendritic architecture (Reeves et al., 1995; Holtzman et al., 1996; Aylward et al., 1997; Haydar and Reeves, 2012). We used a gain-of-function model and demonstrated that overexpression of Dscam is sufficient to reduce cellularity through increased cell death, and that Dscam plays a role in dendrite targeting. While people with DS frequently have visual deficiencies (Creavin and Brown, 2009), this is likely not caused by Dscam-mediated changes to retinal cell number, as overexpression of another minimal critical region gene, Dyrkla, in DS mouse models inhibits caspase 9 and results in an increase in retinal cell number (Laguna et al., 2013). Previous studies have identified a role for Dscam in proper dendrite branching in the hippocampus (Alves-Sampaio et al., 2010) and cortex (Maynard and Stein, 2012), with the latter mirroring changes in the DS brain in which cortical neurons initially project more branches 
than euploid individuals, before adopting an arbor with fewer projections. These studies identify Dscam as an excellent candidate underlying DS pathologies such as hypocellularity observed outside of the retina and dendrite branching defects throughout the brain.

\section{References}

Alves-Sampaio A, Troca-Marín JA, Montesinos ML (2010) NMDAmediated regulation of DSCAM dendritic local translation is lost in a mouse model of Down's syndrome. J Neurosci 30:13537-13548. CrossRef Medline

Amano K, Fujii M, Arata S, Tojima T, Ogawa M, Morita N, Shimohata A, Furuichi T, Itohara S, Kamiguchi H, Korenberg JR, Arata A, Yamakawa K (2009) DSCAM deficiency causes loss of pre-inspiratory neuron synchroneity and perinatal death. J Neurosci 29:2984-2996. CrossRef Medline

Aylward EH, Habbak R, Warren AC, Pulsifer MB, Barta PE, Jerram M, Pearlson GD (1997) Cerebellar volume in adults with Down syndrome. Arch Neurol 54:209-212. CrossRef Medline

Blank M, Fuerst PG, Stevens B, Nouri N, Kirkby L, Warrier D, Barres BA, Feller MB, Huberman AD, Burgess RW, Garner CC (2011) The Down syndrome critical region regulates retinogeniculate refinement. J Neurosci 31:5764-5776. CrossRef Medline

Bruggen B, Meyer A, Boven F, Weiler R, Dedek K (2014) Type 2 wide-field amacrine cells in TH::GFP mice show a homogenous synapse distribution and contact small ganglion cells. Eur J Neurosci. Advanced online publication. doi: 10.1111/ejn.12813.

Chen BE, Kondo M, Garnier A, Watson FL, Püettmann-Holgado R, Lamar DR, Schmucker D (2006) The molecular diversity of Dscam is functionally required for neuronal wiring specificity in Drosophila. Cell 125:607620. CrossRef Medline

Chen SK, Chew KS, McNeill DS, Keeley PW, Ecker JL, Mao BQ, Pahlberg J, Kim B, Lee SC, Fox MA, Guido W, Wong KY, Sampath AP, Reese BE, Kuruvilla R, Hattar S (2013) Apoptosis regulates ipRGC spacing necessary for rods and cones to drive circadian photoentrainment. Neuron 77:503-515. CrossRef Medline

Claes E, Seeliger M, Michalakis S, Biel M, Humphries P, Haverkamp S (2004) Morphological characterization of the retina of the CNGA3 $(-/-) \mathrm{Rho}(-/-)$ mutant mouse lacking functional cones and rods. Invest Ophthalmol Vis Sci 45:20392048. CrossRef Medline

Creavin AL, Brown RD (2009) Ophthalmic abnormalities in children with Down syndrome. J Pediatr Ophthalmol Strabismus 46:76-82. CrossRef Medline

Cvetkovska V, Hibbert AD, Emran F, Chen BE (2013) Overexpression of Down syndrome cell adhesion molecule impairs precise synaptic targeting. Nat Neurosci 16:677-682. CrossRef Medline

de Andrade GB, Long SS, Fleming H, Li W, Fuerst PG (2014) DSCAM localization and function at the mouse cone synapse. J Comp Neurol 522: 2609-2633. CrossRef Medline

Duan X, Krishnaswamy A, De la Huerta I, Sanes JR (2014) Type II cadherins guide assembly of a direction-selective retinal circuit. Cell 158:793-807. CrossRef Medline

Fuerst PG, Koizumi A, Masland RH, Burgess RW (2008) Neurite arborization and mosaic spacing in the mouse retina require DSCAM. Nature 451:470-474. CrossRef Medline

Fuerst PG, Bruce F, Tian M, Wei W, Elstrott J, Feller MB, Erskine L, Singer JH, Burgess RW (2009) DSCAM and DSCAML1 function in self-avoidance in multiple cell types in the developing mouse retina. Neuron 64:484497. CrossRef Medline

Fuerst PG, Harris BS, Johnson KR, Burgess RW (2010) A novel null allele of mouse DSCAM survives to adulthood on an inbred $\mathrm{C} 3 \mathrm{H}$ background with reduced phenotypic variability. Genesis 48:578-584. CrossRef Medline

Fuerst PG, Bruce F, Rounds RP, Erskine L, Burgess RW (2012) Cell autonomy of DSCAM function in retinal development. Dev Biol 361:326-337. CrossRef Medline

Grossman TR, Gamliel A, Wessells RJ, Taghli-Lamallem O, Jepsen K, Ocorr K, Korenberg JR, Peterson KL, Rosenfeld MG, Bodmer R, Bier E (2011) Over-expression of DSCAM and COL6A2 cooperatively generates congenital heart defects. PLoS Genet 7:e1002344. CrossRef Medline

Hahn P, Lindsten T, Ying GS, Bennett J, Milam AH, Thompson CB, Dunaief JL (2003) Proapoptotic bcl-2 family members, Bax and Bak, are essential for developmental photoreceptor apoptosis. Invest Ophthalmol Vis Sci 44:3598-3605. CrossRef Medline

Hattori D, Demir E, Kim HW, Viragh E, Zipursky SL, Dickson BJ (2007) Dscam diversity is essential for neuronal wiring and self-recognition. Nature 449:223-227. CrossRef Medline

Haydar TF, Reeves RH (2012) Trisomy 21 and early brain development. Trends Neurosci 35:81-91. CrossRef Medline

He H, Kise Y, Izadifar A, Urwyler O, Ayaz D, Parthasarthy A, Yan B, Erfurth ML, Dascenco D, Schmucker D (2014) Cell-intrinsic requirement of Dscam1 isoform diversity for axon collateral formation. Science 344: 1182-1186. CrossRef Medline

Holtzman DM, Santucci D, Kilbridge J, Chua-Couzens J, Fontana DJ, Daniels SE, Johnson RM, Chen K, Sun Y, Carlson E, Alleva E, Epstein CJ, Mobley WC (1996) Developmental abnormalities and age-related neurodegeneration in a mouse model of Down syndrome. Proc Natl Acad Sci U S A 93:13333-13338. CrossRef Medline

Huckfeldt RM, Schubert T, Morgan JL, Godinho L, Di Cristo G, Huang ZJ, Wong RO (2009) Transient neurites of retinal horizontal cells exhibit columnar tiling via homotypic interactions. Nat Neurosci 12:35-43. CrossRef Medline

Hughes ME, Bortnick R, Tsubouchi A, Bäumer P, Kondo M, Uemura T, Schmucker D (2007) Homophilic Dscam interactions control complex dendrite morphogenesis. Neuron 54:417-427. CrossRef Medline

Hutchinson KM, Vonhoff F, Duch C (2014) Dscam1 is required for normal dendrite growth and branching but not for dendritic spacing in Drosophila motoneurons. J Neurosci 34:1924-1931. CrossRef Medline

Kay JN, Chu MW, Sanes JR (2012) MEGF10 and MEGF11 mediate homotypic interactions required for mosaic spacing of retinal neurons. Nature 483:465-469. CrossRef Medline

Keeley PW, Reese BE (2010) Morphology of dopaminergic amacrine cells in the mouse retina: independence from homotypic interactions. J Comp Neurol 518:1220-1231. CrossRef Medline

Keeley PW, Sliff BJ, Lee SC, Fuerst PG, Burgess RW, Eglen SJ, Reese BE (2012) Neuronal clustering and fasciculation phenotype in Dscam- and Bax-deficient mouse retinas. J Comp Neurol 520:1349-1364. CrossRef Medline

Khiripet N, Khantuwan W, Jungck JR (2012) Ka-me: a Voronoi image analyzer. Bioinformatics 28:1802-1804. CrossRef Medline

Kim JH, Wang X, Coolon R, Ye B (2013) Dscam expression levels determine presynaptic arbor sizes in Drosophila sensory neurons. Neuron 78:827838. CrossRef Medline

Knop GC, Feigenspan A, Weiler R, Dedek K (2011) Inputs underlying the ON-OFF light responses of type 2 wide-field amacrine cells in TH::GFP mice. J Neurosci 31:4780-4791. CrossRef Medline

Knudson CM, Tung KS, Tourtellotte WG, Brown GA, Korsmeyer SJ (1995) Bax-deficient mice with lymphoid hyperplasia and male germ cell death. Science 270:96-99. CrossRef Medline

Kunzevitzky NJ, Willeford KT, Feuer WJ, Almeida MV, Goldberg JL (2013) Amacrine cell subtypes differ in their intrinsic neurite growth capacity. Invest Ophthalmol Vis Sci 54:7603-7613. CrossRef Medline

Laguna A, Barallobre MJ, Marchena MÁ, Mateus C, Ramírez E, MartínezCue C, Delabar JM, Castelo-Branco M, de la Villa P, Arbonés ML (2013) Triplication of DYRK1A causes retinal structural and functional alterations in Down syndrome. Hum Mol Genet 22:2775-2784. CrossRef Medline

Lefebvre JL, Zhang Y, Meister M, Wang X, Sanes JR (2008) gammaProtocadherins regulate neuronal survival but are dispensable for circuit formation in retina. Development 135:4141-4151. CrossRef Medline

Lefebvre JL, Kostadinov D, Chen WV, Maniatis T, Sanes JR (2012) Protocadherins mediate dendritic self-avoidance in the mammalian nervous system. Nature 488:517-521. CrossRef Medline

Lejeune J, Turpin R, Gautier M (1959) [Chromosomic diagnosis of mongolism]. Arch Fr Pediatr 16:962-963. Medline

Li HL, Huang BS, Vishwasrao H, Sutedja N, Chen W, Jin I, Hawkins RD, Bailey CH, Kandel ER (2009) Dscam mediates remodeling of glutamate receptors in Aplysia during de novo and learning-related synapse formation. Neuron 61:527-540. CrossRef Medline

Liets LC, Eliasieh K, van der List DA, Chalupa LM (2006) Dendrites of rod bipolar cells sprout in normal aging retina. Proc Natl Acad Sci U S A 103:12156-12160. CrossRef Medline

Liu G, Li W, Wang L, Kar A, Guan KL, Rao Y, Wu JY (2009) DSCAM 
functions as a netrin receptor in commissural axon pathfinding. Proc Natl Acad Sci U S A 106:2951-2956. CrossRef Medline

Livet J, Weissman TA, Kang H, Draft RW, Lu J, Bennis RA, Sanes JR, Lichtman JW (2007) Transgenic strategies for combinatorial expression of fluorescent proteins in the nervous system. Nature 450:56-62. CrossRef Medline

Ly A, Nikolaev A, Suresh G, Zheng Y, Tessier-Lavigne M, Stein E (2008) DSCAM is a netrin receptor that collaborates with DCC in mediating turning responses to netrin-1. Cell 133:1241-1254. CrossRef Medline

Masland RH (2012) The neuronal organization of the retina. Neuron 76: 266-280. CrossRef Medline

Matsuda T, Cepko CL (2004) Electroporation and RNA interference in the rodent retina in vivo and in vitro. Proc Natl Acad Sci U S A 101:16-22. CrossRef Medline

Matsuoka RL, Nguyen-Ba-Charvet KT, Parray A, Badea TC, Chédotal A, Kolodkin AL (2011a) Transmembrane semaphorin signalling controls laminar stratification in the mammalian retina. Nature 470:259-263. CrossRef Medline

Matsuoka RL, Chivatakarn O, Badea TC, Samuels IS, Cahill H, Katayama K, Kumar SR, Suto F, Chédotal A, Peachey NS, Nathans J, Yoshida Y, Giger RJ, Kolodkin AL (2011b) Class 5 transmembrane semaphorins control selective Mammalian retinal lamination and function. Neuron 71:460473. CrossRef Medline

Matsuoka RL, Jiang Z, Samuels IS, Nguyen-Ba-Charvet KT, Sun LO, Peachey NS, Chédotal A, Yau KW, Kolodkin AL (2012) Guidance-cue control of horizontal cell morphology, lamination, and synapse formation in the mammalian outer retina. J Neurosci 32:6859-6868. CrossRef Medline

Matthews BJ, Kim ME, Flanagan JJ, Hattori D, Clemens JC, Zipursky SL, Grueber WB (2007) Dendrite self-avoidance is controlled by Dscam. Cell 129:593-604. CrossRef Medline

Maynard KR, Stein E (2012) DSCAM contributes to dendrite arborization and spine formation in the developing cerebral cortex. J Neurosci 32: 16637-16650. CrossRef Medline

Michalakis S, Schäferhoff K, Spiwoks-Becker I, Zabouri N, Koch S, Koch F, Bonin M, Biel M, Haverkamp S (2013) Characterization of neurite outgrowth and ectopic synaptogenesis in response to photoreceptor dysfunction. Cell Mol Life Sci 70:1831-1847. CrossRef Medline

Millard SS, Lu Z, Zipursky SL, Meinertzhagen IA (2010) Drosophila dscam proteins regulate postsynaptic specificity at multiple-contact synapses. Neuron 67:761-768. CrossRef Medline

Miyazaki J, Takaki S, Araki K, Tashiro F, Tominaga A, Takatsu K, Yamamura K (1989) Expression vector system based on the chicken beta-actin promoter directs efficient production of interleukin-5. Gene 79:269-277. CrossRef Medline

Morales Diaz HD (2014) Down syndrome cell adhesion molecule is important for early development in Xenopus tropicalis. Genesis 52:849-857. CrossRef Medline

Neves G, Zucker J, Daly M, Chess A (2004) Stochastic yet biased expression of multiple Dscam splice variants by individual cells. Nat Genet 36:240246. CrossRef Medline

Okawa H, Hoon M, Yoshimatsu T, Della Santina L, Wong RO (2014) Illuminating the multifaceted roles of neurotransmission in shaping neuronal circuitry. Neuron 83:1303-1318. CrossRef Medline

Péquignot MO, Provost AC, Sallé S, Taupin P, Sainton KM, Marchant D, Martinou JC, Ameisen JC, Jais JP, Abitbol M (2003) Major role of BAX in apoptosis during retinal development and in establishment of a functional postnatal retina. Dev Dyn 228:231-238. CrossRef Medline

Purohit AA, Li W, Qu C, Dwyer T, Shao Q, Guan KL, Liu G (2012) Down syndrome cell adhesion molecule (DSCAM) associates with uncoordinated-5C (UNC5C) in netrin-1-mediated growth cone collapse. J Biol Chem 287:27126-27138. CrossRef Medline

Rahmani Z, Blouin JL, Créau-Goldberg N, Watkins PC, Mattei JF, Poissonnier M, Prieur M, Chettouh Z, Nicole A, Aurias A, et al. (1990) Down syndrome critical region around D21S55 on proximal 21q22.3. Am J Med Genet Suppl 7:98-103. Medline

Ramon y Cajal S (1893) La re'tine des verte'bre's. La Cellule 9:119-257.

Randlett O, MacDonald RB, Yoshimatsu T, Almeida AD, Suzuki SC, Wong RO, Harris WA (2013) Cellular requirements for building a retinal neuropil. Cell Rep 3:282-290. CrossRef Medline

Reese BE, Keeley PW (2014) Design principles and developmental mechanisms underlying retinal mosaics. Biol Rev Camb Philos Soc. Advanced online publication. doi: 10.1111/brv.12139. Medline

Reeves RH, Irving NG, Moran TH, Wohn A, Kitt C, Sisodia SS, Schmidt C, Bronson RT, Davisson MT (1995) A mouse model for Down syndrome exhibits learning and behaviour deficits. Nat Genet 11:177-184. CrossRef Medline

Rodieck RW (1991) The density recovery profile: a method for the analysis of points in the plane applicable to retinal studies. Vis Neurosci 6:95-111. CrossRef Medline

Samuel MA, Zhang Y, Meister M, Sanes JR (2011) Age-related alterations in neurons of the mouse retina. J Neurosci 31:16033-16044. CrossRef Medline

Samuel MA, Voinescu PE, Lilley BN, de Cabo R, Foretz M, Viollet B, Pawlyk B, Sandberg MA, Vavvas DG, Sanes JR (2014) LKB1 and AMPK regulate synaptic remodeling in old age. Nat Neurosci 17:1190-1197. CrossRef Medline

Schmucker D, Chen B (2009) Dscam and DSCAM: complex genes in simple animals, complex animals yet simple genes. Genes Dev 23:147-156. CrossRef Medline

Schmucker D, Clemens JC, Shu H, Worby CA, Xiao J, Muda M, Dixon JE, Zipursky SL (2000) Drosophila Dscam is an axon guidance receptor exhibiting extraordinary molecular diversity. Cell 101:671-684. CrossRef Medline

Schramm RD, Li S, Harris BS, Rounds RP, Burgess RW, Ytreberg FM, Fuerst PG (2012) A novel mouse Dscam mutation inhibits localization and shedding of DSCAM. PLoS One 7:e52652. CrossRef Medline

Soba P, Zhu S, Emoto K, Younger S, Yang SJ, Yu HH, Lee T, Jan LY, Jan YN (2007) Drosophila sensory neurons require Dscam for dendritic selfavoidance and proper dendritic field organization. Neuron 54:403-416. CrossRef Medline

Stacy RC, Demas J, Burgess RW, Sanes JR, Wong RO (2005) Disruption and recovery of patterned retinal activity in the absence of acetylcholine. J Neurosci 25:9347-9357. CrossRef Medline

Sun LO, Jiang Z, Rivlin-Etzion M, Hand R, Brady CM, Matsuoka RL, Yau KW, Feller MB, Kolodkin AL (2013) On and off retinal circuit assembly by divergent molecular mechanisms. Science 342:1241974. CrossRef Medline

Yamagata M, Sanes JR (2008) Dscam and Sidekick proteins direct laminaspecific synaptic connections in vertebrate retina. Nature 451:465-469. CrossRef Medline

Yamagata M, Sanes JR (2010) Synaptic localization and function of Sidekick recognition molecules require MAGI scaffolding proteins. J Neurosci 30: 3579-3588. CrossRef Medline

Yamagata M, Sanes JR (2012) Expanding the Ig superfamily code for laminar specificity in retina: expression and role of contactins. J Neurosci 32:14402-14414. CrossRef Medline

Yamakawa K, Huot YK, Haendelt MA, Hubert R, Chen XN, Lyons GE, Korenberg JR (1998) DSCAM: a novel member of the immunoglobulin superfamily maps in a Down syndrome region and is involved in the development of the nervous system. Hum Mol Genet 7:227-237. CrossRef Medline

Yimlamai D, Konnikova L, Moss LG, Jay DG (2005) The zebrafish down syndrome cell adhesion molecule is involved in cell movement during embryogenesis. Dev Biol 279:44-57. CrossRef Medline

Zhu H, Hummel T, Clemens JC, Berdnik D, Zipursky SL, Luo L (2006) Dendritic patterning by Dscam and synaptic partner matching in the Drosophila antennal lobe. Nat Neurosci 9:349-355. CrossRef Medline 